Management international

International Management

Gestiòn Internacional

\title{
Les déterminants de la complexité des systèmes d'information comptables des dirigeants de PME : contingences culturelles et endogénéité
}

\section{Determinants of the complexity of accounting information systems \\ of managers of SMEs: cultural contingencies and endogeneity}

Los factores determinantes de la complejidad de los sistemas de información contables de los dirigentes de PYMES: contingencias culturales y endogeneidad

\author{
Adrien B. Bonache, Philippe Chapellier, Zouhour Ben Hamadi et Abdallah \\ Mohammed
}

Volume 19, numéro 3, printemps 2015

URI : https://id.erudit.org/iderudit/1043008ar

DOI : https://doi.org/10.7202/1043008ar

\section{Aller au sommaire du numéro}

Éditeur(s)

HEC Montréal

Université Paris Dauphine

ISSN

1206-1697 (imprimé)

1918-9222 (numérique)

Découvrir la revue

Citer cet article

Bonache, A. B., Chapellier, P., Ben Hamadi, Z. \& Mohammed, A. (2015). Les déterminants de la complexité des systèmes d'information comptables des dirigeants de PME : contingences culturelles et endogénéité. Management international / International Management / Gestiòn Internacional, 19(3), 148-168. https://doi.org/10.7202/1043008ar

\section{Résumé de l'article}

Le premier objectif est d'étudier le lien entre les dimensions de la culture nationale et la complexité des systèmes d'information comptables (SIC) des dirigeants de PME. Le second est de contribuer au débat sur la présence potentielle de biais d'endogénéité dans les précédentes études réalisées sur le thème. Une régression multiple et un test d'Hausman ont été mobilisés en utilisant les réponses de 276 dirigeants de PME françaises, tunisiennes et syriennes. Les quatre dimensions de la culture proposées par Hofstede sont des déterminants significatifs de la complexité des SIC. Le test d'Hausman révèle que l'existence d'endogénéité est peu plausible.
Tous droits réservés (C) Management international / International Management / Gestión Internacional, 2015
Ce document est protégé par la loi sur le droit d'auteur. L'utilisation des services d’Érudit (y compris la reproduction) est assujettie à sa politique d'utilisation que vous pouvez consulter en ligne. 


\section{Les déterminants de la complexité des systèmes d'information comptables des dirigeants de PME : contingences culturelles et endogénéité}

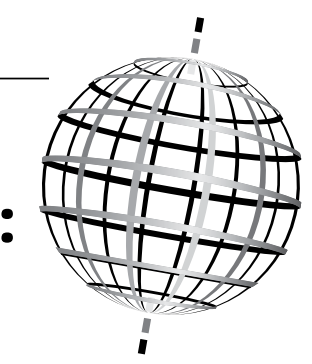

\section{Determinants of the complexity of accounting information systems of managers of SMEs: cultural contingencies and endogeneity}

\section{Los factores determinantes de la complejidad de los sistemas de información contables de los dirigentes de PYMES: contingencias culturales y endogeneidad}

\author{
ADRIEN B. BONACHE \\ IAE DIJON \\ Université de Bourgogne
}

\author{
PHILIPPE CHAPELLIER \\ $M R M$ - Labex Entreprendre \\ Université de Montpellier
}

\author{
ZOUHOUR BEN HAMADI \\ $M R M$ - Labex Entreprendre \\ Université de Montpellier
}

\author{
ABDALLAH MOHAMMED \\ LEMNA \\ Université de Nantes
}

\begin{abstract}
RÉSUMÉ
Le premier objectif est d'étudier le lien entre les dimensions de la culture nationale et la complexité des systèmes d'information comptables (SIC) des dirigeants de PME. Le second est de contribuer au débat sur la présence potentielle de biais d'endogénéité dans les précédentes études réalisées sur le thème. Une régression multiple et un test d'Hausman ont été mobilisés en utilisant les réponses de 276 dirigeants de PME françaises, tunisiennes et syriennes. Les quatre dimensions de la culture proposées par Hofstede sont des déterminants significatifs de la complexité des SIC. Le test d'Hausman révèle que l'existence d'endogénéité est peu plausible.
\end{abstract}

Mots clés : complexité des systèmes d'information comptables, petites et moyennes entreprises, contingences culturelles, endogénéité.

\section{Abstract}

First, in the context of small and mediumsized enterprises (SME), the study aimed at showing cultural contingencies of the sophistication of accounting information systems (AIS). Second, the study aimed at contributing to the debate on the potential endogeneity bias in the results of previous studies. A multiple regression analysis and a Hausman test were performed on 276 responses. The respondents are top managers of French, Syrian or Tunisian SME. The results show that Hofstede's cultural dimensions are significant antecedents of the sophistication of AIS. The Hausman test reveals the absence of endogeneity bias in the previous studies.

Key words: sophistication of accounting information systems, small and medium-sized enterprises, cultural contingency, endogeneity.

\section{Resumen}

El primer objetivo es estudiar el vínculo entre las dimensiones de la cultura nacional y la complejidad de los sistemas de información contables (SIC) de los dirigentes de PYMES. El segundo es contribuir al debate acerca de la presencia potencial de sesgo de endogeneidad en los anteriores estudios realizados sobre este tema. Se han mobilizado una regresión múltiple y un test de Hausman, utilizando las respuestas de 276 dirigentes de PYMES francesas, tunecinas y sirias. Las cuatro dimensiones de la cultura propuestas por Hofstede son determinantes significativos de la complejidad de los SIC. El test de Hausman revela que la existencia de endogeneidad es poco plausible.

Palabras clave: complejidad de los sistemas de información contables, PYMES, contingencias culturales, endogeneidad.

\begin{abstract}
«The relationship between the design of MCS and national culture represents an extension of contingencybased research from its organizational foundations into more sociological concerns.» (Chenhall, 2003, p. 152)

«A current issue of potential concern in theory-based management accounting research is the extent to which endogeneity limits the validity of empirical testing of models.» (Chenhall et Moers, 2007, p. 173)
\end{abstract}

1. Selon Cameron et Quinn (2006, p. 16-17), le manque d'intérêt des chercheurs et des praticiens pour la dimension culturelle est dû au fait qu'ils ne sont pas conscients de son importance. Ils prendraient
G parcourant les recherches sur les déterminants de la complexité des systèmes d'information comptables des PME, on peut être surpris par deux faits.

Premièrement, les études sur le thème faisant intervenir des variables culturelles sont rares (Harrison et McKinnon, 1999; Chenhall, 2007)1 ${ }^{1}$. Le manque de prise en compte de ces variables est surprenant car leur inclusion dans le champ

conscience de son intérêt lorsque la culture est remise en cause, s'ils sont confrontés à une nouvelle culture, ou s'il en est fait explicitement mention dans un modèle. 
de la recherche comptable en PME présente des intérêts managériaux et théoriques. D'une part, du fait de la mondialisation, des PME qui opéraient avant dans un seul pays, se voient confrontées aujourd'hui à des questions importantes (Harrison et McKinnon, 1999; MacArthur, 2006) : Doiventelles exporter sur leurs nouveaux sites de production ou de commercialisation étrangers les systèmes d'information comptables du pays d'origine? Doivent-elles les modifier eu égard à des déterminants culturels ? Doivent-elles directement «adopter» les systèmes d'information comptables étrangers? D'autre part, il existe des fondements théoriques d'une contingence culturelle de la complexité des systèmes d'information comptables (Chenhall, 2003). La prise en compte des dimensions culturelles permettrait de faire avancer notre connaissance sur le thème. La majorité des études réalisées ont été conduites dans un seul pays. Citons, à titre d'exemples, les études de Bergeron (1996) en France, Van Caillie (2002) en Belgique, Lavigne et St-Pierre (2002) au Canada, Nyengue Edimo (2006) au Cameroun et Affès et Chabchoub (2007) en Tunisie. Ainsi, les modèles utilisés pourraient être sous-spécifiés car ils ne prennent pas en compte les dimensions culturelles. Or, en s'appuyant sur les travaux d'Hofstede (1980), il est possible de soutenir que les dimensions de la culture nationale pourraient être un déterminant de la complexité des systèmes d'information comptables des PME.

Le second constat part de récents papiers en comptabilité et contrôle de gestion (Chenhall et Moers, 2007; García Lara et al., 2007; Larcker et Rusticus, 2010; Tucker, 2011; Lennox et al., 2012) susceptibles de remettre en cause certains résultats d'études antérieures. Ces résultats pourraient être biaisés par l'endogénéité de variables que les auteurs ont supposées exogènes. À notre connaissance, aucune étude réalisée sur les déterminants de la complexité des systèmes d'information comptables des PME n'a mobilisé de tests pour montrer l'absence de biais d'endogénéité. En l'occurrence, si la complexité du système d'information comptable et au moins un de ses déterminants sont influencés par une variable omise, les résultats des études omettant cette variable doivent être considérés comme biaisés. Par exemple, les dimensions culturelles (Chenhall, 2003), l'incertitude économique et technique (Chapman, 1997) ou l'âge de l'organisation (Davila, 2005) peuvent impacter la structure de l'organisation, donc sa taille, et la complexité des systèmes d'information comptables. Si les études précédentes sur les déterminants de la complexité des systèmes d'information comptables des PME ont omis au moins une de ces variables, cette omission peut jeter un doute sur la fiabilité de leurs résultats.

Partant de ce double constat de l'absence de la dimension «culture nationale» dans les modèles antérieurs et d'un risque de biais dû à l'endogénéité de variables, notre étude vise à répondre aux deux questions suivantes :

- La complexité des systèmes d'information comptables des PME est-elle déterminée par des dimensions de la culture nationale?
- Les études antérieures sur les déterminants de la complexité des systèmes d'information comptables des PME sont-elles biaisées par l'endogénéité de variables considérées jusqu'alors comme exogènes?

Pour répondre à ces questions, nous avons utilisé les données individuelles de trois études réalisées sur la complexité des systèmes d'information comptables des PME et leurs déterminants par Chapellier (1996), Ben Hamadi et Chapellier (2012) et Chapellier, Mohammed et Teller (2013) et des proxys permettant de prendre en compte les déterminants dont la non-considération pourrait biaiser les résultats.

En réalisant cette étude, nous souhaitons combler deux manques dans la littérature sur les déterminants de la complexité des systèmes d'information comptables des PME. Premièrement, nous pensons qu'en prenant en compte les dimensions culturelles, nous pourrons donner un éclairage multiculturel sur les déterminants de leur complexité. Cela «déplace la conversation» (Huff, 1999) et «ouvre un champ (Locke et Golden-Biddle, 1997). Les études antérieures se sont appuyées sur la théorie de la contingence structurelle pour expliquer la complexité des SIC des PME en se centrant sur des variables telles que la taille et l'âge de l'entreprise, et/ou individuelle en évaluant le rôle de déterminants tels que l'expérience ou le niveau de formation du dirigeant. Pourtant, en suivant Hofstede (1980), il est possible de supposer que certaines dimensions de la culture nationale influencent la complexité des systèmes d'information comptables. Par exemple, l'évitement de l'incertitude, une des dimensions retenues par Hofstede (1980), qui rend compte du degré auquel les membres d'un groupe culturel cherchent à éviter les situations ambiguës, pourrait influencer la complexité du système d'information comptable : si cette dimension de la culture est forte dans un pays, en moyenne, le contrôle pourrait être plus formel et donc les systèmes d'information comptables plus complexes. En testant la relation entre les déterminants culturels et la complexité des systèmes d'information comptables, notre étude pourrait ainsi ouvrir un nouveau champ de recherche. Combler ce manque est aussi important sur le plan managérial, car nos résultats pourraient éclairer des dirigeants de petites et moyennes entreprises cherchant à développer leur activité à l'international. Nos résultats pourraient les inciter à adapter la complexité de leur système d'information comptable aux contextes culturels nationaux. De même, nos résultats pourraient conduire les éditeurs de progiciels comptables à créer des logiciels modulables et adaptables en fonction des cultures nationales.

Deuxièmement, en testant l'endogénéité de la taille de l'entreprise, nous avons pour objectif de contribuer au débat sur la fiabilité des études antérieures réalisées sur le thème des déterminants de la complexité des systèmes d'information comptables des PME. Au mieux de nos connaissances, alors que de nombreux papiers récents soulignent le risque de biais d'endogénéité dans les études en comptabilité et contrôle de 
gestion (Chenhall et Moers, 2007; García Lara et al., 2007; Larcker et Rusticus, 2010; Tucker, 2011; Lennox et al., 2012), aucune recherche sur les déterminants de la complexité des systèmes d'information comptables n'a cherché à évaluer ce risque. En suivant plusieurs auteurs (Chapman, 1997; Chenhall, 2003; Davila, 2005), il est possible de suggérer que la taille de l'entreprise soit endogène. Tester que la taille de l'entreprise ne soit pas déterminée par d'autres variables influençant la complexité des systèmes d'information comptables permettra de contribuer au débat.

Après avoir présenté le cadre conceptuel et les hypothèses de la recherche, nous exposons la méthodologie mise en œuvre et les résultats obtenus. Nous discutons enfin les apports et limites de cette étude, ainsi que les avenues de recherches futures.

\section{Cadre conceptuel et fondement de nos hypothèses}

Avant de présenter les hypothèses de la recherche, nous définissons les petites et moyennes entreprises et la complexité du système d'information comptable afin de délimiter notre champ d'investigation et présentons les apports et les limites de la théorie de la contingence pour notre travail.

\section{LES PETITES ET MOYENNES ENTREPRISES COMME OBJETS DE RECHERCHE}

Les trois recherches mobilisées dans cet article portent sur le système d'information comptable de petites et moyennes entreprises. Ces recherches définissent ce type d'organisations comme des entreprises juridiquement indépendantes et disposant d'un effectif compris entre 10 et 100 salariés (Chapellier, 1996), 10 et 250 salariés (Chapellier, Mohammed et Teller, 2013) et 10 et 300 salariés (Chapellier et Ben Hamadi, 2012). D'une manière très classique, les critères retenus dans les trois cas concernent d'une part le nombre de salariés et d'autre part l'indépendance de l'entreprise en termes de capital. Sont donc exclues de ces études les filiales, succursales ou divisions d'entreprises plus importantes. La différence dans la définition de la taille maximale de la petite et moyenne entreprise d'une étude à l'autre nous a conduits à prendre certaines précautions dans l'analyse de nos résultats. Mais cette différence ne remet pas en question d'un point de vue statistique la faisabilité de l'étude.

\section{UNE DÉFINITION DE LA COMPLEXITÉ DU SYSTÈME D'INFORMATION COMPTABLE}

Bon nombre des chercheurs qui se sont intéressés aux systèmes d'information comptables ont utilisé le critère du degré de complexité pour les caractériser (Abdel-Kader et Luther, 2008; Al-Omiri et Drury, 2007; Tillema, 2005; Germain, 2004).

Une analyse détaillée de ces travaux montre que l'élaboration d'un score de complexité est guidée par deux considérations principales. En premier lieu, elle est fonction du champ de recherche délimité par les chercheurs. Certains adoptent une approche essentiellement structurelle du système d'information comptable et prennent en compte des indicateurs relatifs au support logistique (Nyengue Edimo, 2006; Saboly, 1994). D'autres se concentrent sur l'examen de la complexité associée à la production et/ou à l'utilisation des données comptables (Lavigne et St-Pierre, 2002). D'autres enfin intègrent la variable «diffusion des données» (Bergeron, 1996; Lavigne et St-Pierre, 2002).

En second lieu, le choix des indicateurs d'opérationnalisation de la complexité des systèmes d'information comptables est guidé par la recherche d'indicateurs discriminants, c'est-à-dire par la recherche d'indicateurs qui font émerger des pratiques différenciées. Par exemple, dans le cadre d'études sur les petites et moyennes entreprises, la formalisation ou non du service comptable apparaît comme un indicateur discriminant, mais il ne l'est plus dès lors que les entreprises ont atteint une taille plus importante dans la mesure où elles disposent alors systématiquement d'un service comptable formalisé.

Selon leur centre d'intérêt et le contexte de l'étude, les chercheurs déterminent donc un degré de complexité des systèmes d'information comptables qui peut renvoyer à des contenus très différents. Les trois recherches, dont les données sont ensuite utilisées, retiennent le degré de complexité pour caractériser le système d'information comptable. Mais elles s'appuient sur différentes dimensions pour y parvenir (tableau 1).

La comparaison des dimensions retenues dans les trois recherches permet de constater qu'une seule dimension a été étudiée par les trois à la fois : «la production des données comptables de gestion ». Pour que l'étude utilisant les données de ces trois recherches soit réalisable, nous limitons la définition de la complexité du système d'information comptable à cette dimension. La complexité du système d'information comptable est donc caractérisée au regard des données comptables de gestion produites et disponibles dans l'entreprise. Cette décision, permettant d'homogénéiser la mesure de la complexité du système d'information comptable dans les trois études, est possible grâce à la mise à disposition par les auteurs de leur base de données mais elle constitue une limite importante de notre travail. La recherche en comptabilité a successivement étudié l'utilité, l'importance, la disponibilité pour finalement conclure que ce qui est important, c'est l'utilisation. Par exemple Chenhall et Morris (1986) demandaient au répondant le caractère utile des différentes caractéristiques des informations présentées. Gul (1991) demandait au répondant d'évaluer l'utilité de caractéristiques d'informations mais aussi le degré auquel le SIC fournissait chacune de ces caractéristiques d'information. Mia et Chenhall (1994), Chong (1996, 1998) et Chong et Chong (1997) ont quant à eux demandé aux répondants d'évaluer le degré auquel ils utilisaient les différentes caractéristiques d'information fournie par le SIC. Ces différentes questions font bien ressortir la nuance ainsi que la portée au plan théorique entre 


\section{TABLEAU 1}

\section{Différences dans la mesure du degré de complexité du système d'information comptable}

\section{entre les trois études}

\begin{tabular}{c|c|c|c}
\hline $\begin{array}{c}\text { Études } \\
\text { Acceptions de la complexité du SIC }\end{array}$ & $\begin{array}{c}\text { Chapellier, } \\
\text { Chapellier } \\
\mathbf{( 1 9 9 6 )}\end{array}$ & $\begin{array}{c}\text { Mohmed et Teller } \\
\mathbf{( 2 0 1 3 )}\end{array}$ & $\begin{array}{c}\text { Ben Hamadi et } \\
\text { Chapellier (2012) }\end{array}$ \\
\hline Support logistique du SIC & & $\mathrm{X}$ & $\mathrm{X}$ \\
\hline Production des données comptables & $\mathrm{X}$ & $\mathrm{X}$ & $\mathrm{X}$ \\
\hline Utilisation des informations comptables & $\mathrm{X}$ & $\mathrm{X}$ & $\mathrm{X}$ \\
\hline Diffusion des données comptables & & & \\
\hline \hline
\end{tabular}

importance, utilité, disponibilité et utilisation ${ }^{2}$. Ainsi, utiliser la production des données comptables pour que l'étude comparative soit réalisable constitue une limite dont nous sommes conscients et que nous tenterons de réduire en testant les liens entre les mêmes variables explicatives et le score d'utilisation obtenu dans les deux études ayant mesuré cette variable (Chapellier, 1996 et Chapellier, Mohammed et Teller, 2013) afin de vérifier si les résultats obtenus restent identiques.

Ces études sont en revanche homogènes sur deux points. Premièrement, les trois études mesurent la complexité au regard de la fréquence, du degré de détail, de la diversité et du délai de production des données comptables de gestion produites. Deuxièmement, cette homogénéité se retrouve dans la définition qu'elles donnent des données comptables de gestion. Les trois études considèrent les données provenant de la comptabilité générale et celles élaborées sur la base et autour de cette comptabilité. Il s'agit de données qui concernent les situations intermédiaires, les données du système de calcul de coûts, budgétaires, d'analyse d'écarts, et celles présentes dans les tableaux de bord.

\section{LA THÉORIE DE LA CONTINGENCE DES SYSTÈMES D'INFORMATION COMPTABLES ET SES LIMITES}

Le système d'information comptable a trouvé naissance et s'est développé dans les organisations tayloriennes. C'est pourquoi il a longtemps, et parfois implicitement, été considéré par les chercheurs comme globalement et universellement pertinent et cohérent. Un passage de la conception universaliste à la compréhension contingente des SIC s'est toutefois imposé dans la littérature au début des années 1970. Il a conduit les chercheurs du domaine à s'interroger sur la capacité des systèmes d'information comptables à se différencier

2. Nous remercions le réviseur de la revue pour son analyse très complète sur ce point, analyse dont nous nous sommes largement inspirés pour souligner cette limite. selon les spécificités de la structure et du contexte où ils sont développés. On peut sur ce point citer les travaux précurseurs de Khandwalla (1972), Sathe (1975) ou de Bruns et Waterhouse (1975). Mais la théorie de la contingence structurelle néglige l'influence possible des acteurs. D'autres auteurs (Bergeron, 1996; Lavigne, 2002; Flacke et Segbers, 2005; Nyengue Edimo, 2006; Affès et Chabchoub, 2007; Santin et Van Caillie, 2008) ont proposé pour cette raison d'élargir le cadre de recherche sur les systèmes d'information comptables à la théorie de la contingence comportementale. Dans cette perspective, les caractéristiques individuelles de chaque acteur viennent modérer les effets des variables structurelles. Un individu peut donc être actif par rapport à la situation et non contraint par elle. Ainsi, et plus précisément, les caractéristiques organisationnelles et de contexte peuvent certes, dans une certaine mesure, limiter et déterminer les choix de l'acteur. Mais ce dernier n'en reste pas moins libre et doué d'intentionnalité. Il dispose d'une marge de liberté (Crozier et Friedberg, 1977). En ce sens, Lorino (1995) souligne l'importance de la prise en considération de l'autonomie cognitive des acteurs : chacun d'entre eux détient une part de la connaissance nécessaire à l'action. Il doit donc disposer en outre d'une autonomie, c'est-à-dire d'une part de pouvoir.

C'est dire que la lecture contingente ne peut rester mécanique et déterministe (Bouquin, 1997). Elle apporte une contribution à la compréhension des systèmes d'information comptables (Germain, 2004). Diverses recherches montrent l'existence de liens entre les caractéristiques organisationnelles et environnementales de l'entreprise, le profil des acteurs de la PME et, enfin, les caractéristiques du SIC (Raymond, 1985; Covaleski et al., 1996; Reid et Smith, 2000; Laitinen, 2001; Chenhall, 2003; Bescos et al., 2004; Gerdin, 2005; Jänkälä, 2007; Al-Omiri et Drury, 2007; Abdel Kader et Luther, 2008). L'hypothèse dominante de la littérature semble rester que le degré et les propriétés 
de formalisation des systèmes d'information comptables utilisés par les dirigeants de PME varient fortement en fonction de variables structurelles et individuelles.

Deux limites importantes à cette littérature apparaissent toutefois. Premièrement, les études faisant intervenir des variables culturelles sont rares (Harrison et McKinnon, 1999; Chenhall, 2007). Pourtant, il existe des fondements théoriques d'une contingence culturelle de la complexité des systèmes d'information comptables (Chenhall, 2003). La prise en compte de dimensions culturelles permettrait de faire avancer notre connaissance sur les déterminants de la complexité des systèmes d'information comptables car la majorité des études réalisées sur le thème ont été conduites dans un seul pays. Ainsi, les modèles utilisés ne prenant pas en compte les dimensions culturelles peuvent être sous-spécifiés. En s'appuyant sur les travaux d'Hofstede (1980), il est possible de soutenir que les dimensions de la culture nationale pourraient être un déterminant de la complexité des systèmes d'information comptables.

Deuxièmement, de récents papiers en comptabilité et contrôle de gestion (Chenhall et Moers, 2007; García Lara et al, 2007; Larcker et Rusticus, 2010; Tucker, 2011; Lennox et al., 2012) sont susceptibles de remettre en cause certains résultats d'études antérieures utilisant cette théorie. Leurs résultats pourraient être biaisés par l'endogénéité de variables que les auteurs ont supposées exogènes. Une première solution pour répondre à cette limite serait d'intégrer dans un modèle tous les facteurs de contingence susceptibles d'influencer la complexité des SIC. Cette solution n'est cependant pas réalisable pour deux raisons. D'une part, la prise en compte de toutes les variables de contingence risquerait de faire apparaître des problèmes de multi-colinéarité (inflation de la variance et instabilité des coefficients). D'autre part, le «fléau de la dimension » (Bellman, 1961) rendrait difficile l'estimation non paramétrique de l'effet des facteurs de contingence sur la complexité des systèmes d'information comptables. Une seconde solution passe par l'adoption d'une procédure permettant de tester l'existence de biais d'endogénéité.

Au mieux de nos connaissances, les précédentes études sur la complexité des SIC n'ont pas intégrer les dimensions culturelles comme facteur de contingences, et n'ont pas mobilisé une procédure permettant d'évaluer les biais dus à l'omission de variables influençant simultanément la complexité des systèmes d'information comptables et les déterminants inclus dans leurs modèles. Partant de ce double constat notre étude vise à répondre aux deux questions suivantes :

- La complexité des systèmes d'information comptables des PME est-elle déterminée par des dimensions de la culture nationale?

- Les études antérieures sur les déterminants de la complexité des systèmes d'information comptables des PME sont-elles biaisées par l'endogénéité de variables considérées jusqu'alors comme exogènes?

\section{HYPothÈSES DE LA RECHERCHE ET VARIABLES DE CONTRÔLE}

\section{Contingences culturelles et complexité du SIC}

Les théories de la contingence structurelle et individuelle laissent supposer qu'il est possible de transférer d'un pays à un autre un système d'information comptable si les structures des organisations et les caractéristiques des acteurs sont semblables. Au début des années 2000, des articles de presse ont par exemple conseillé aux entreprises américaines d'adopter les pratiques allemandes de comptabilité de gestion supposées plus efficaces (MacArthur, 2006). Or, suivant cet auteur, le choix d'un système d'information comptable plus ou moins complexe nécessite une analyse coût-bénéfice prenant en compte de nombreux facteurs, dont la culture nationale.

La culture rendrait compte d'un ensemble de croyances, valeurs, hypothèses et significations partagées (Schein, 1985). Elle serait perçue comme la programmation collective de l'esprit qui distingue les membres d'un groupe social des membres d'autres groupes sociaux (Hofstede, 1991, p. 262). Mais l'opérationnalisation du concept est sujette à débat (Rousseau, 1990; O'Reilly et al., 1991). Certains chercheurs affirment que la culture ne peut être étudiée de façon pertinente avec des techniques quantitatives (Schein, 1985), voire «qu'elle nécessite d'être observée, plus que d'être mesurée » (Schein, 1996, p. 229). D'autres voient dans la mise en œuvre d'analyses statistiques une méthode permettant de contribuer de façon pertinente à l'étude de la culture (Rousseau, 1990; Hofstede, 1998). D'autres enfin considèrent que des études de cas qualitatives et des méthodes quantitatives peuvent être combinées pour contribuer à l'exploration des effets de la culture (Denison et Misra, 1995; Denison et Spreitzer, 1991).

Au-delà de ce débat, les travaux sur la relation entre la culture nationale et les systèmes d'information comptables sont rares (Harrison et McKinnon, 1999). Or la culture pourrait constituer une forme de coordination informelle définissant des règles floues (Camerer et Vepsalainen, 1988, pp. 116-117) qui pourrait compléter ou se substituer au contrôle formel. Suivant un raisonnement marginaliste, le contrôle formel ne prend en compte que les clauses les moins coûteuses à spécifier et dont les coûts d'exploitation sont les plus élevés. La culture pourrait permettre d'aller au-delà des contrôles formels via des règles tacites suffisamment claires pour guider le comportement attendu dans des situations non spécifiées car imprévues. La culture nationale pourrait guider les individus vers des comportements (point focaux) grâce à des valeurs, normes et hypothèses fondamentales (principes focaux).

La culture pourrait donc constituer une variable importante permettant d'expliquer la complexité des SIC. Pour réaliser une étude interculturelle sur le thème, il est nécessaire d'identifier quelles composantes de la culture sont déterminantes du phénomène étudié (Harrison et McKinnon, 1999, p. 485). Pour ce faire, comme la plupart des études réalisées sur le thème, nous nous appuyons sur les quatre dimensions de la culture identifiées par Hofstede (1980) : évitement de 
l'incertitude, individualisme / collectivisme, masculinité / féminité et distance hiérarchique.

L'évitement de l'incertitude rend compte du degré auquel les membres de l'organisation cherchent à éviter les situations incertaines et ambiguës. Si cet évitement est fort, le contrôle est plus formel et donc le système d'information comptable plus complexe. Cet argument nous amène à formuler l'hypothèse H1 : Lorsque l'évitement de l'incertitude est fort, la complexité du système d'information comptable est plus élevée.

La dimension opposant individualisme et collectivisme représente le degré auquel les individus sont intégrés dans des groupes sociaux, notamment les organisations. Lorsque le sens du collectif est développé, un contrôle et une organisation claniques tendent à se substituer à un contrôle et une organisation formels. Lorsque l'individualisme est élevé, les relations sociales sont distendues et les outils de contrôle suppléent le manque de cohésion sociale et d'harmonie. Partant de cet argument, l'hypothèse $\mathrm{H} 2$ suivante peut être émise : Plus une nation est collectiviste, moins la complexité du système d'information comptable est élevée.

La dimension opposant la féminité à la masculinité rend compte du degré auquel les valeurs sur lesquelles les hommes ont généralement des scores plus élevés sont prédominantes : assurance, vénalité, indifférence au bien-être d'autrui et à la qualité de vie. Dans les nations dites «féminines», les aspects sociaux et le respect de la vie privée sont valorisés, alors que travail, compétitivité et agressivité sont valorisés dans les sociétés dites «masculines». Dans les nations dites «féminines », le contrôle serait plus informel et aurait une étendue plus restreinte. Cet argument nous amène à formuler $\mathrm{H} 3$ : Plus une nation est «féminine», moins la complexité du système d'information comptable est élevée.

La distance hiérarchique rend compte du degré auquel est socialement acceptée une distribution inégale du pouvoir. Lorsque cette distance est faible, la centralisation l'est aussi, les structures hiérarchiques sont plus plates. Il n'est pas possible à partir de ces arguments de formuler une hypothèse sur le signe de la relation entre distance hiérarchique et complexité du système d'information comptable. Ainsi, cette situation incertaine nous conduit à formuler l'hypothèse $\mathrm{H} 4$ : La distance hiérarchique n'est pas reliée à la complexité du système d'information comptable.

\section{Variables de contrôle et complexité du SIC}

Hambrick et Mason (1984) ont proposé un modèle intégrateur permettant de comprendre comment des stimuli identiques (facteurs de contingence structurels ou environnementaux) pouvaient amener à des réponses diverses. Cela peut être dû à des facteurs de contingences individuels. Par exemple, l'incertitude n'est pas seulement la résultante de facteurs contextuels externes en interaction. Cette incertitude est aussi causée par des facteurs cognitifs tels que le niveau de formation (Chapman, 1997) ou l'expérience du dirigeant (Nadeau et al., 1988). Seront ainsi testés les liens entre la complexité du SIC en PME et ces deux variables de contrôle individuelles.

\section{Le niveau de formation du dirigeant}

Négrier (2004) souligne que la formation concourt à l'établissement d'une base cognitive et à la légitimation de l'autonomie de l'activité des acteurs à l'intérieur des organisations. Une majorité d'études réalisées sur le thème de la complexité du SIC des dirigeants de PME met en avant que les dirigeants possédant un niveau de formation élevé disposent de SIC plus complexes (Saboly, 1994). Les individus les plus formés toléreraient un niveau d'abstraction plus élevé et auraient une plus grande habileté pour intégrer des masses plus importantes d'informations (Chapellier, 2011). Nous proposons de ce fait d'intégrer le niveau de formation des dirigeants de PME comme variable de contrôle.

\section{L'expérience du dirigeant}

Reix (1984) ne trouve aucune relation entre le degré de production des données comptables de gestion et l'expérience du dirigeant. Mais d'autres auteurs relèvent un lien significatif et négatif entre ces deux variables (Nadeau et al., 1988). Pour ces derniers auteurs, cette relation s'explique par une double logique : d'une part, les dirigeants les moins expérimentés sont souvent les plus formés et d'autre part, les décideurs en situation d'apprentissage seraient demandeurs d'un volume d'informations plus conséquent au départ qui diminue et se stabilise ensuite. Nous proposons de ce fait d'intégrer l'expérience des dirigeants de PME comme variable de contrôle.

La littérature relève par ailleurs l'influence de facteurs structurels sur la complexité des SIC. Seront ainsi testés les liens entre la complexité du SIC des PME et deux variables de contrôle structurelles identifiées par la littérature.

\section{La taille de l'entreprise}

De nombreuses recherches ont montré l'existence de liens entre la taille des PME et les caractéristiques de leur système de contrôle. Nobre (2001) relève par exemple l'existence de deux stades du contrôle de gestion en fonction de la taille de la PME : le premier concerne les entreprises de moins de 100 salariés, le second regroupe celles qui comptent entre 100 et 250 salariés. Ce résultat rejoint ceux des auteurs de la théorie du cycle de vie de la firme (Moores et Yuen, 2001). Ces auteurs relèvent l'existence de différents stades de développement des organisations induisant des conceptions différentes des systèmes d'information comptables à l'œuvre au cours des étapes du cycle de vie. Deux arguments expliquent cette relation. D'une part, la taille constitue un facteur de contingence pertinent si l'on s'appuie sur les concepts de coût de transaction et de contrôle informel (Davila, 2005). Pour des organisations de taille modeste, la coordination peut se faire informellement par ajustement mutuel ou supervision directe (Chiapello, 1996; Mintzberg, 2006). Mais quand la taille croît, il est souhaitable de 
formaliser la communication, le contrôle et la coordination en utilisant un système d'information comptable plus complexe, pour diminuer les coûts de transaction dus à la coordination informelle ${ }^{3}$. Les modes de gestion informels de la petite entreprise laisseraient pour cette raison place à un système de plus en plus formalisé au fur et à mesure que l'entreprise crôt (Flamholtz, 1986) se rapprochant ainsi des systèmes observés dans les grandes entreprises. D'autre part, l'accroissement de la taille permettrait à l'organisation d'accéder à plus de ressources et compétences et lui permettrait ainsi d'enrichir son système d'information comptable et de le rendre plus complexe. Le recrutement d'un contrôleur de gestion maîtrisant des outils de comptabilité de gestion contribuerait à la complexification du système d'information comptable (Al Omiri et Drury, 2007; Abdel-Kader et Luther, 2008). Ces arguments nous poussent à supposer un lien significatif positif entre la taille de l'organisation et la complexité du système d'information comptable. Nous proposons de ce fait d'intégrer la taille des PME comme variable de contrôle.

\section{L'âge de l'entreprise}

Par ailleurs, plusieurs études ont montré l'existence de liens entre l'âge de l'entreprise et ses pratiques de gestion (Holmes et Nicholls, 1989). L'idée avancée par Mintzberg (1982) et Dupuy et al. (1989) est que l'âge de l'entreprise fait inévitablement référence à son passé, à son histoire et que les événements qui ont marqué cette histoire (changement de propriétaire, difficultés) influencent les pratiques de gestion. Suivant le modèle des phases de croissance de Greiner (1972), l'apparition d'un système de contrôle de gestion n'interviendrait qu'après un certain nombre d'années. Durant la première phase de créativité, l'organisation entrepreneuriale se caractériserait par des liens informels. Après résolution d'une crise de leadership due au besoin de capacités managériales, la deuxième phase, dite de direction, se caractériserait par une organisation plus formalisée et standardisée à mesure que le temps passe. Après une crise d'autonomie due à un besoin de délégation des responsabilités, la troisième phase, dite de délégation, se caractériserait par des contrôles uniquement financiers et un management par exception. Cette phase déboucherait sur une crise de contrôle due à des responsables «trop» autonomes. L'organisation entrerait alors dans une phase de coordination caractérisée par des procédures de planification, une articulation en centres de responsabilité, une centralisation de la fonction des systèmes d'information et une multiplication des outils de gestion. Cette phase caractérisée par une complexification du système d'information comptable se terminerait par une crise d'accumulation des procédures complexes qui déclencherait à terme une crise de saturation psychologique des responsables. Greiner (1972) propose ainsi un modèle des phases de croissance soulignant

3. Dans une petite organisation, le dirigeant peut voir chaque salarié et discuter avec chacun d'eux et chaque personne dans l'organisation peut se coordonner informellement avec les autres. À mesure que le nombre de membres $\mathrm{N}$ de l'organisation s'accroît, il est difficile de se coordonner informellement. Les transactions s'accroissent plus rapidement que le nombre de personnes $\mathrm{N}$, car l'existence d'une relation significative mais non linéaire entre l'âge des organisations et leur système de contrôle de gestion. Selon lui, la croissance de l'entreprise est un phénomène ponctué par des «phases d'évolution» caractérisées par une croissance stable marquée par des changements lents et progressifs. Entre ces phases stables de croissance ont lieu des «phases de révolution» se caractérisant par des changements abrupts et des sauts qualitatifs. Cette relation non linéaire est expliquée par Davila (2005) avec un processus proche des processus d'enaction, de sélection et de rétention (Weick, 1979). Il indique que le temps offre un espace à l'organisation lui permettant d'apprendre et d'améliorer son système d'information comptable. L'organisation expérimente des pratiques de gestion alternatives, choisit la plus judicieuse et développe un outil pour stocker et diffuser l'utilisation de la pratique choisie. Ces arguments permettent de supposer que l'âge est lié à la complexité du système d'information comptable. Nous avons donc retenu l'âge de l'entreprise comme variable de contrôle.

\section{Cadre méthodologique}

La méthode de cueillette des données, l'opérationnalisation des variables, les statistiques descriptives et la justification de la méthode d'analyse sont successivement présentées.

\section{LA MÉTHODE DE CUEILLETTE DES DONNÉES}

Les données individuelles utilisées dans notre étude proviennent des travaux de Chapellier (1996), Chapellier, Mohammed et Teller (2013) et Ben Hamadi et Chapellier (2012). Nous avons retenu ces trois études pour deux raisons. Premièrement, toutes trois ont utilisé les mêmes échelles pour mesurer la complexité des systèmes d'information comptables. Deuxièmement, elles ont été réalisées dans trois pays culturellement différents.

Chapellier (1996) a tiré son échantillon d'un annuaire de petites et moyennes entreprises de la Région LanguedocRoussillon (France). Un courrier papier a été envoyé à 396 petites et moyennes entreprises de 10 à 100 salariés et indépendantes. Ce courrier expliquait l'objet et le contexte de l'étude. Une semaine après, l'auteur demandait par téléphone un rendez-vous avec le dirigeant. La collecte a été réalisée en face à face du $1^{\text {er }}$ février au 31 juillet 1993 auprès de 113 dirigeants de PME. L'auteur de l'étude posait les questions et remplissait le questionnaire. Cette administration du questionnaire en face à face a permis de voir si les répondants comprenaient bien les questions. En cas d'hésitations ou de contradictions, l'auteur a pu approfondir ses explications pour améliorer la fiabilité des réponses. Par ailleurs, l'auteur a

elles sont fonction de la combinaison de deux personnes parmi les $\mathrm{N}$ membres de l'organisation : $\mathrm{C}_{\mathrm{N}}^{2}=\frac{\mathrm{N} !}{2 !(\mathrm{N}-2) !}=\frac{\mathrm{N}(\mathrm{N}-1)}{2}$. Si ces transactions sont à l'origine des coûts du contrôle informel, la pertinence de ce type de contrôle décroît rapidement avec la taille. 
contrôlé la fiabilité des réponses de 41 des 113 dirigeants en interrogeant leurs comptables salariés. Les réponses des deux types d'acteurs étaient très corrélées sur la production des données comptables, parfois décalées sur leur utilisation.

Ben Hamadi et Chapellier (2012) ont tiré leur échantillon d'un annuaire des entreprises industrielles de la région de Tunis (Tunisie). Ces petites et moyennes entreprises industrielles ont été contactées, dans un premier temps, par Ben Hamadi via leur adresse électronique. Aucune réponse positive ne lui étant parvenue, elle a décidé de faire du «porte à porte» et d'administrer directement le questionnaire aux dirigeants. 71 entretiens ont été réalisés entre le $1^{\mathrm{er}}$ janvier 2007 et le 31 juillet 2007. Cette administration du questionnaire en face à face a permis de vérifier la sincérité des réponses (certaines réponses se répétant pour tenter de repérer des incohérences) et de demander au dirigeant des explications sur ces éventuelles incohérences.

Chapellier, Mohammed et Teller (2013) ont tiré leur échantillon aléatoirement d'une liste de PME de la Chambre de l'industrie d'Alep (Syrie). Ces PME ont tout d'abord été sollicitées par Mohammed via un message électronique en langue arabe et anglaise présentant l'objet et le contexte de la recherche. En l'absence de réponse ou d'adresse électronique, il a ensuite appelé les entreprises par téléphone et demandé un rendez-vous aux dirigeants. Pour inciter les dirigeants à répondre au questionnaire, le chercheur s'est présenté comme un doctorant de l'Institut d'Administration des Entreprises de Nice en France menant une étude doctorale sur le système d'information comptable des petites et moyennes entreprises syriennes et a insisté sur la confidentialité des données et sur le fait que la recherche serait publiée en France et en langue française sans aucune identification possible des entreprises participantes. Les questionnaires ont été administrés en face à face du 15 juin 2008 au 15 septembre 2008 auprès de 92 dirigeants de PME.
Le recours à des méthodes quantitatives pour réaliser ce type d'étude se justifie par la relative simplicité des propriétés à étudier, en même temps que par la recherche de relations entre un grand nombre d'objets et d'une description de ces relations dans un modèle généralisable. Les statistiques descriptives réalisées ont permis de décrire les caractéristiques des organisations et des acteurs observés, et de synthétiser les données recueillies. Au-delà d'une description immédiate des pratiques, le recours aux statistiques explicatives a également permis d'analyser les liens entre les concepts, c'est-à-dire les relations entre les variables à expliquer - la complexité du système d'information comptable - et les variables explicatives - les facteurs de contingences.

Le mode d'administration du questionnaire par entretien direct a été retenu dans les trois études car il autorise un recueil d'informations plus complet, plus détaillé et de meilleure qualité que l'enquête postale ou par Internet (Bergeron, 1996; Evrard et al., 2009). Il a permis de poser des questions complexes, longues, variées et d'apporter certaines précisions utiles au répondant et à la validité de l'étude grâce à la possibilité de reformuler, de clarifier et d'expliquer si nécessaire aux répondants les questions difficiles ou mal comprises (Thiétart, 2007). Administrer ces questionnaires en face à face a donc permis d'interroger à la fois la complexité de forme et la complexité de sens des données comptables. De plus, la confidentialité qui entoure la comptabilité en PME aurait probablement conduit la plupart des dirigeants à refuser de répondre à un questionnaire reçu par voie postale ou électronique. Le fait de pouvoir expliquer et justifier en face à face l'objet de l'étude a généré de la confiance et a rendu possible la réalisation des trois recherches.

TABLEAU 2

L'opérationnalisation des variables dans les trois études

\begin{tabular}{|c|c|c|c|}
\hline Variables de l'étude & Chapellier (1996) & $\begin{array}{c}\text { Chapellier, Mohammed et } \\
\text { Teller (2013) }\end{array}$ & $\begin{array}{l}\text { Ben Hamadi et Chapellier } \\
\text { (2012) }\end{array}$ \\
\hline Complexité du SIC & \multicolumn{3}{|c|}{$\begin{array}{c}\text { Diversité, degré de détail, fréquence et délai de production des données de comptabilité } \\
\text { générale, des situations intermédiaires, du système de calcul de coûts, des données } \\
\text { budgétaires, d'analyse des écarts et des tableaux de bord (voir annexe 1). }\end{array}$} \\
\hline $\begin{array}{l}\text { Niveau de formation } \\
\text { du dirigeant }\end{array}$ & $\begin{array}{c}\leq \mathrm{au} \mathrm{Bac} / \mathrm{Bac}+2 \mathrm{et}+3 / \\
\geq \mathrm{à} \mathrm{Bac}+4\end{array}$ & $\begin{array}{c}<\mathrm{au} \mathrm{Bac} / \mathrm{Bac} \text { à Bac +2 / } \\
\geq \text { à Bac +4 }\end{array}$ & $\begin{array}{c}<\mathrm{au} \mathrm{Bac} / \mathrm{Bac} / \mathrm{Bac}+2 \mathrm{et}+3 / \\
\geq \text { à Bac }+4\end{array}$ \\
\hline Expérience du dirigeant & \multicolumn{3}{|c|}{ Nombre d'années passées par le dirigeant à la tête d'une entreprise. } \\
\hline Taille de l'entreprise & \multicolumn{3}{|c|}{ Nombre de salariés équivalent temps plein lors du dernier exercice. } \\
\hline Âge de l'entreprise & \multicolumn{3}{|c|}{ Nombre d'années d'existence depuis sa création. } \\
\hline
\end{tabular}

${ }^{*}$ Concernant le niveau de formation, les découpages différents entre les études nous ont conduits à créer une variable dichotomique «niveau de formation» prenant la valeur 1 pour les individus disposant d'un « $\mathrm{Bac}+4$ ou plus » et la valeur 0 sinon. 


\section{Opérationnalisation des variables}

Le tableau 2 montre comment la complexité du système d'information comptable et les variables de contingence ont été opérationnalisées dans les trois études synthétisées dans ce papier.

La complexité du système d'information comptable rend compte de sa capacité à apporter un large spectre d'informations pertinentes pour contrôler, planifier et prendre des décisions afin de créer de la valeur pour l'entreprise (Tillema, 2005; Abdel-Kader et Luther, 2008). Pour opérationnaliser cette variable expliquée, les trois études ont évalué la diversité, le niveau de détail, la fréquence et le délai de production des données comptables. Ces données peuvent être issues de la comptabilité générale, des systèmes de calcul des coûts et budgétaires, de l'analyse des écarts et/ou des tableaux de bord. L'annexe 1 présente le questionnaire utilisé pour évaluer la production des informations comptables, seule composante de la complexité des systèmes d'information comptables commune aux trois études.

Cependant, pour les raisons développées précédemment, l'utilisation des informations comptables est aussi très importante, comme le montre l'évolution des recherches dans ce champ (Chenhall et Morris, 1986; Gul, 1991; Mia et Chenhall, 1994; Chong, 1996; Chong et Chong 1997). Pour vérifier la robustesse de nos résultats et lever partiellement cette limite, nous avons réalisé les mêmes traitements en retenant les mêmes variables explicatives et de contrôle, mais en prenant en considération le score d'utilisation du système d'information comptable comme variable expliquée à la place du score de production. Cela

\section{TABLEAU 3}

Valeurs des proxys des dimensions de la culture nationale proposées par Hofstede

\begin{tabular}{l|c|c|c}
\hline & France & $\begin{array}{c}\text { Tunisie } \\
\text { (Maroc/ } \\
\text { Lybie) }\end{array}$ & Syrie \\
\hline $\begin{array}{l}\text { Évitement de } \\
\text { l'incertitude }\end{array}$ & 86 & $68 / 68$ & 60 \\
\hline $\begin{array}{l}\text { Collectivisme / } \\
\text { Individualisme }\end{array}$ & 71 & $46 / 38$ & 35 \\
\hline $\begin{array}{l}\text { Féminité / } \\
\text { Masculinité }\end{array}$ & 43 & $53 / 52$ & 52 \\
\hline $\begin{array}{l}\text { Distance } \\
\text { hiérarchique }\end{array}$ & 68 & $70 / 80$ & 80 \\
\hline \hline
\end{tabular}

nous a conduits à exclure de l'analyse les données issues de l'étude de Ben Hamadi et Chapellier (2012) puisque cette étude n'a pas retenu «l'utilisation » pour évaluer la complexité des SIC.

Nous avons enfin pris en considération des proxys mesurant les quatre dimensions de la culture. Pour la France et la Syrie, nous avons directement pris les mesures sur le site http://geert-hofstede.com ${ }^{4}$. Hofstede ne donne en revanche pas de mesures de ces quatre dimensions pour la Tunisie.

\section{TABLEAU 4}

\section{Comparaison des études compilées}

\begin{tabular}{c|c|c|c}
\hline Article & Chapellier (1996) & Chapellier et al. (2013) & $\begin{array}{c}\text { Ben Hamadi et Chapellier } \\
\text { (2012) }\end{array}$ \\
\hline Échantillon & 113 PME françaises & 92 PME syriennes & 71 PME tunisiennes \\
\hline $\begin{array}{c}\text { Niveau de formation } \\
\text { Inférieur à Bac+4 }\end{array}$ & 77 & 42 & 31 \\
BAC +4 et $>$ & 36 & 50 & 40 \\
\hline Expérience moyenne & 15,69 & 11,81 & 13,41 \\
\hline Taille des PME & $10-100$ salariés & $10-250$ salariés & $10-300$ salariés \\
\hline Effectif moyen & 41,14 & 80,47 & 104,35 \\
(écart-type) & $(24,03)$ & $(72,48)$ & $(85,42)$ \\
\hline Âge moyen de la PME & 28,13 & 17,36 & 21,41 \\
(écart-type) & $(16,48)$ & $(16,01)$ & $(19,88)$ \\
\hline \hline
\end{tabular}

4. Pour comprendre la construction et le fondement des mesures de la culture nationale d'Hofstede, le lecteur peut se référer à Hofstede et al., 1990 (p. 287-288). 


\section{TABLEAU 5}

\section{Statistiques descriptives de forme et de dispersion}

\begin{tabular}{l|c|c|c|c|c}
\hline & Moyenne & Médiane & Ecart-type & Minimum & Maximum \\
\hline Complexité & 41,09 & 40 & 17,02 & 0 & 79 \\
Âge & 22,81 & 18 & 17,84 & 1 & 105 \\
Taille & 70,51 & 45 & 67,19 & 10 & 300 \\
Secteur & 0,79 & 1 & 0,41 & 0 & 1 \\
Niveau de formation & 0,46 & 0 & 0,50 & 0 & 1 \\
Expérience & 1,88 & 2 & 0,79 & 1 & 3 \\
Distance hiérarchique & 69,39 & 69 & 8,16 & 61 & 80 \\
Masculinité & 51,76 & 52 & 9,96 & 42 & 67 \\
Individualisme & 53,07 & 40 & 19,22 & 35 & 76 \\
Evitement de l'incertitude & 60,99 & 60 & 13,95 & 40 & 75 \\
Incertitude économique & 0,88 & 0,63 & 1,05 & 0,01 & 2,60 \\
\hline \hline
\end{tabular}

Nous avons pour cette raison été conduits, et cela constitue une limite de notre travail, à retenir les mesures réalisées par Hofstede pour le pays le plus proche culturellement de la Tunisie à savoir le Maroc. Pour limiter l'impact de cette limite et vérifier la sensibilité de nos résultats, nous avons réalisé les traitements à l'identique d'une part sans les données tunisiennes, et d'autre part en utilisant les dimensions de la culture nationale d'un autre pays proche géographiquement et culturellement de la Tunisie à savoir la Libye.

Enfin, nous avons utilisé des proxys pour des variables instrumentales. Nous avons utilisé une variable dichotomique indiquant le secteur d'activité de la PME. Cette variable prenant la valeur 1 lorsque la PME est industrielle, la valeur 0 sinon. Nous avons ensuite mobilisé la variance du taux d'inflation durant la période de collecte des données pour mesurer l'incertitude économique. Ces deux variables qui peuvent impacter les variables de contingence structurelles ont été mobilisées pour tester des biais potentiels dus à l'endogénéité de la taille de l'entreprise.

L'opérationnalisation des variables a permis de présenter comment ont été mesurées les variables d'intérêt de notre étude. Les statistiques descriptives permettent ensuite de donner un aperçu synthétique des données recueillies.

\section{Statistiques Descriptives}

Le tableau 4 présente les caractéristiques générales des trois échantillons, tandis que le tableau 5 présente les caractéristiques de position et de dispersion principales de notre étude. Il permet d'apprécier l'absence de données aberrantes dans notre échantillon.

La matrice de corrélation réalisée sur la base des réponses des 276 dirigeants est présentée dans le tableau 6. Cette matrice fait apparaître une colinéarité entre les dimensions culturelles «distance hiérarchique», «masculinité» et «évitement de l'incertitude».

Le point suivant permet de justifier notre méthode d'analyse.

\section{JUSTIFICATION DE LA MÉTHODE D’ANALYSE}

Pour tester nos hypothèses, nous avons réalisé une estimation des coefficients d'une régression linéaire à partir des informations concernant les 276 individus interrogés : 113 observés en France par Chapellier (1996), 92 en Syrie par Chapellier, Mohammed et Teller (2013) et 71 en Tunisie par Ben Hamadi et Chapellier (2012). L'accès à la base de données de chacune des trois études a permis d'homogénéiser les mesures et de synthétiser numériquement les résultats de ces différents articles.

Dans un premier temps, nous avons estimé avec la méthode des moindres carrés le modèle en prenant en compte toutes les variables retenues dans l'étude. L'estimation des effets de toutes ces variables n'étaient pas mathématiquement possible eu égard à une colinéarité des dimensions de la culture entre elles. Pour cette raison, nous avons testé quatre modèles, un pour chacune des variables culturelles. Les modèles testés sont donc les suivants : 
Complexité du $\mathrm{SIC}_{\mathrm{i}}=\beta_{0}+\beta_{1}$ Âge $+\beta_{2}$ Taille $_{\mathrm{i}}+\beta_{3}$ Expérience $_{\mathrm{i}}$ $+\beta_{4}$ Formation $_{\mathrm{i}}+\beta_{5}$ Niveau de formation $_{\mathrm{i}}+\beta_{6}$ Évitement de l'incertitude ${ }_{\mathrm{i}}+\varepsilon_{\mathrm{i}}$

Complexité du SIC $_{\mathrm{i}}=\beta_{0}+\beta_{1}$ Âge $+\beta_{2}$ Taille $_{\mathrm{i}}+$ $\beta_{3}$ Expérience $_{i}+\beta_{4}$ Formation $_{i}+\beta_{5}$ Niveau de formation $_{i}+$ $\beta_{6}$ Individualisme $_{\mathrm{i}}+\varepsilon_{\mathrm{i}}$

Complexité du $\mathrm{SIC}_{\mathrm{i}}=\beta_{0}+\beta_{1}$ Âge $+\beta_{2}$ Taille $_{\mathrm{i}}+\beta_{3}$ Expérience $_{\mathrm{i}}+$ $\beta_{4}$ Formation $_{\mathrm{i}}+\beta_{5}$ Niveau de formation $_{\mathrm{i}}+\beta_{6}$ Masculinité $_{\mathrm{i}}+\varepsilon_{\mathrm{i}}$

Complexité du SIC $_{i}=\beta_{0}+\beta_{1}$ Âge $+\beta_{2}$ Taille $_{i}+$ $\beta_{3}$ Expérience $_{\mathrm{i}}+\beta_{4}$ Formation $_{\mathrm{i}}+\beta_{5}$ Niveau de formation $_{\mathrm{i}}+$ $\beta_{6}$ Distance Hiérarchique $_{i}+\varepsilon_{\mathrm{i}}$

Avec le paramètre $\beta_{\mathrm{j}}$ à estimer montrant l'impact d'un facteur de contingence étudié sur la complexité du système d'information comptable. Par exemple, $\beta_{1}$ est la pente de la relation entre l'âge de l'entreprise et la complexité du système d'information comptable. i indique qu'il s'agit de la réponse du i ìme dirigeant, $i=1, \ldots, 276$.

Le secteur d'activité et l'incertitude économique peuvent expliquer théoriquement la taille de l'entreprise. Ces deux variables instrumentales sont valides car elles sont corrélées avec la taille, sans être corrélées avec les résidus des modèles 1a, 1b, 1c et 1d. Nous avons donc testé l'endogénéité de la taille (Hausman, 1978) par le biais d'une comparaison entre les modèles ci-dessus ( $1 \mathrm{a}, 1 \mathrm{~b}, 1 \mathrm{c}$ et $1 \mathrm{~d})$ et le modèle à deux équations suivant (2) :
Complexité du SIC $_{\mathrm{i}}=\beta_{0}+\beta_{1}$ Âge $+\beta_{2}$ Taille $_{\mathrm{i}}+$ $\beta_{3}$ Expérience $_{\mathrm{i}}+\beta_{4}$ Formation $_{\mathrm{i}}+\beta_{5}$ Niveau de formation ${ }_{\mathrm{i}}$ $+\beta_{6}$ Variables Culturelles $+\varepsilon_{\mathrm{i}}$

Taille $_{\mathrm{i}}=\alpha_{0}+\alpha_{1}$ Secteur $_{\mathrm{i}}+\alpha_{2}$ Incertitude $_{\mathrm{i}}+\mathrm{u}_{\mathrm{i}}$

Avec le paramètre à estimer montrant l'impact d'un facteur de contingence ou d'une variable instrumentale sur la taille de l'entreprise.

Ce test nous a permis de contrôler l'absence de biais d'endogénéité dans les quatre sous-modèles (1a, 1b, 1c et 1d). Nous présentons les résultats obtenus dans le point 3 .

\section{Résultats et robustesse de l'étude}

\section{CONTINGENCES ET COMPLEXITÉ DES SYSTÈMES D'INFORMATION COMPTABLES}

Culture nationale et complexité des systèmes d'information comptables

Les hypothèses 1, 2 et 3 suggèrent un effet positif des dimensions de la culture «évitement de l'incertitude», «individualisme» et «masculinité» sur la complexité du système d'information comptable des dirigeants de PME. L'hypothèse 4 figure que la distance hiérarchique n'est pas reliée à la complexité du système d'information comptable.

\section{TABLEAU 6}

\section{Matrice de corrélation}

\begin{tabular}{|c|c|c|c|c|c|c|c|c|c|c|}
\hline & 2 & 3 & 4 & 5 & 6 & 7 & 8 & 9 & 10 & 11 \\
\hline 1-Complexité & 0,00 & $0,19^{* *}$ & $-0,15^{*}$ & $0,30^{* * *}$ & $-0,13^{*}$ & $-0,33^{* * *}$ & $-0,17^{* *}$ & $0,32^{* * *}$ & $0,18^{* *}$ & $-0,11$ \\
\hline 2-Âge & & $-0,01$ & $-0,16^{* *}$ & $-0,06$ & $0,42^{* * *}$ & $-0,26^{* * *}$ & $-0,15^{*}$ & $0,26^{* * *}$ & $0,16^{* *}$ & $-0,11$ \\
\hline 3-Taille & & & $0,27^{* * *}$ & $0,24^{* * * *}$ & $-0,07$ & $0,24^{* * *}$ & $0,38^{* * *}$ & $-0,35^{* * *}$ & $-0,38^{* * *}$ & $0,35^{* * *}$ \\
\hline 4-Secteur & & & & $0,16^{* *}$ & $-0,18^{* *}$ & $0,54^{* * *}$ & $0,51^{* * * *}$ & $-0,62^{* * *}$ & $-0,52^{* * * *}$ & $0,44^{* * *}$ \\
\hline 5-Niv de formation & & & & & $-0,27^{* * *}$ & $0,19^{* *}$ & $0,20^{* * * *}$ & $-0,23^{* * *}$ & $-0,20^{* * *}$ & $0,17^{* *}$ \\
\hline 6-Expérience & & & & & & $-0,21^{* * * *}$ & $-0,11$ & $0,19^{* *}$ & 0,11 & $-0,07$ \\
\hline 7-Dis. hiérarchique & & & & & & & $0,41^{* * * *}$ & $-0,90^{* * *}$ & $-0,44^{* * *}$ & $0,23^{* * *}$ \\
\hline 8-Masculinité & & & & & & & & $-0,76^{* * *}$ & $-1,00^{* * *}$ & $0,98^{* * *}$ \\
\hline 9- Individualisme & & & & & & & & & $0,78^{* * *}$ & $-0,62^{* * *}$ \\
\hline 10- Evit. de l'incert. & & & & & & & & & & $-0,98^{* * *}$ \\
\hline 11- Incert éco. & & & & & & & & & & \\
\hline
\end{tabular}

Notes : ${ }^{* * *},{ }^{* *}$ et ${ }^{*}$ indiquent que la valeur de $\mathrm{p}$ associée à l'hypothèse de nullité du coefficient de corrélation est inférieure à $1 \%, 5 \%$ et $10 \%$, respectivement. Ces valeurs de p ont été corrigées en suivant la procédure de Benjamini et Yekutieli (2001) pour diminuer le taux de faux résultats positifs. 


\section{TABLEAU 7}

\section{Effet des facteurs de contingences structurels, individuels et culturels sur la complexité du système d'information comptable $(\mathrm{N}=276)$}

\begin{tabular}{|c|c|c|c|c|c|c|c|c|}
\hline \multirow[t]{2}{*}{ Modèles } & \multicolumn{2}{|c|}{ 1a : test de H1 } & \multicolumn{2}{|c|}{$1 b$ : test de $\mathrm{H} 2$} & \multicolumn{2}{|c|}{$1 c$ : test de $\mathrm{H3}$} & \multicolumn{2}{|c|}{ 1d : test de H4 } \\
\hline & Coefficient & (ES) & Coefficient & (ES) & Coefficient & (ES) & Coefficient & (ES) \\
\hline Constante & 6,82 & $(5,45)$ & $10,83^{* *}$ & $(3,72)$ & $62,51^{* * *}$ & $(5,64)$ & $102,54^{* * *}$ & $(8,60)$ \\
\hline Âge de l'entreprise & $-0,04$ & 0,06 & $-0,09^{*}$ & $(0,05)$ & $-0,04$ & $(0,06)$ & $-0,07$ & $(0,05)$ \\
\hline Taille de l'entreprise & $0,06^{* * *}$ & $(0,01)$ & $0,07^{* * *}$ & $(0,01)$ & $0,06^{* * *}$ & $(0,01)$ & $0,06^{* * *}$ & $(0,01)$ \\
\hline $\begin{array}{l}\text { Niveau de formation } \\
\text { du dirigeant }\end{array}$ & $7,25^{* * *}$ & $(2,03)$ & $8,97^{* * *}$ & $(1,90)$ & $7,15^{* * *}$ & $(2,03)$ & $8,79^{* * *}$ & $(1,94)$ \\
\hline Expérience du dirigeant & $-0,63$ & $(1,32)$ & $-1,41$ & $(1,23)$ & $-0,61$ & $(1,33)$ & $-1,68$ & $(1,26)$ \\
\hline Dimension culturelle & $0,43^{* * *}$ & $(0,07)$ & $0,45^{* * *}$ & $(0,05)$ & $-0,57^{* * *}$ & $(0,10)$ & $-0,95^{* * *}$ & $(0,11)$ \\
\hline $\begin{array}{l}\text { Coefficient de } \\
\text { détermination ajusté }\end{array}$ & \multicolumn{2}{|c|}{$24,18 \%$} & \multicolumn{2}{|c|}{$34,75 \%$} & \multicolumn{2}{|c|}{$23,44 \%$} & \multicolumn{2}{|c|}{$31,62 \%$} \\
\hline
\end{tabular}

Notes : ${ }^{*},{ }^{* *}$ et ${ }^{* * *}$ rendent compte de valeurs de $\mathrm{p}$ associées aux hypothèses présentées inférieures à $10 \%, 5 \%$ et $1 \%$ respectivement. Les variables colinéaires ont été retirées. ES est l'erreur standard.

L'hypothèse 1 admet que l'évitement de l'incertitude a un impact positif sur la complexité du système d'information comptable. Le tableau 7 montre que l'effet de cette dimension sur la complexité du SIC est significatif et positif $(0,43$; $\mathrm{p}<0,001)$. Une PME d'un pays dans lequel la dimension «évitement de l'incertitude» est $10 \%$ plus élevée, dispose en moyenne d'un système d'information comptable avec une note de complexité supérieure de $4,3 \%$. Ce résultat ne permet pas de rejeter l'hypothèse 1 .

L'hypothèse 2 admet que l'individualisme a un impact positif sur la complexité du système d'information comptable. Le tableau 7 montre que l'effet de cette dimension de la culture sur la complexité du SIC est significatif et positif $(0,45 ; \mathrm{p}<0,001)$. Une PME d'un pays culturellement plus individualiste de $10 \%$ dispose en moyenne d'un système d'information comptable avec une note de complexité supérieure de 4,5\%. Ainsi, l'hypothèse H2 n'est pas invalidée.

L'hypothèse 3 suggère que la masculinité de la culture d'une nation a un effet positif sur la complexité du système d'information comptable des PME situées sur ce territoire. L'analyse fait apparaître une relation certes significative, mais négative entre la masculinité et la complexité du système d'information comptable $(-0,57 ; p<0,001)$. Une PME d'un pays culturellement plus «masculin» de $10 \%$ dispose en moyenne d'un système d'information comptable avec une note de complexité inférieure de 5,7\%. Cela nous conduit à ne pas accepter l'hypothèse 3 postulant que cette dimension de la culture est reliée positivement à la complexité des systèmes d'information comptables.

L'hypothèse 4 suggère que la distance hiérarchique n'est pas reliée à la complexité du système d'information comptable.
Au terme des tests réalisés, il apparaît que l'effet de la distance hiérarchique sur la complexité du système d'information comptable est significatif et négatif $(-0,95 ; \mathrm{p}<0,001)$. Une PME d'un pays dans lequel la dimension «distance hiérarchique» est $10 \%$ plus élevée, dispose en moyenne d'un système d'information comptable avec une note de complexité inférieure de $9,5 \%$. Cela nous conduit à ne pas accepter l'hypothèse 4 postulant l'absence de lien entre cette dimension de la culture et la complexité des systèmes d'information comptables.

En somme, nos résultats montrent que chacune des quatre dimensions de la culture retenues influence la complexité du système d'information comptable.

Variables de contrôle et complexité des systèmes d'information comptables

La littérature suggère que plus le niveau de formation du dirigeant est élevé, plus le système d'information comptable de l'organisation dont il est responsable est complexe. En outre, plus son expérience est élevée, plus la complexité du SIC est faible.

Le tableau 7 montre que le niveau de formation du dirigeant a un impact positif et significatif au seuil de $1 \%$ sur la complexité du SIC pour chacun des 4 modèles testés (1a, $1 b, 1 c$ et 1d).

En revanche, l'expérience a un effet négatif mais non significatif sur la complexité des systèmes d'informations comptables.

La littérature suggère ensuite un effet positif de la taille de l'entreprise sur la complexité du système d'information comptable. Le tableau 7 rend compte de cet impact significatif 


\section{FIGURE 1}

\section{Évolution en escalier du coefficient de corrélation mobile entre la taille de l'entreprise et la complexité du système d'information comptable}

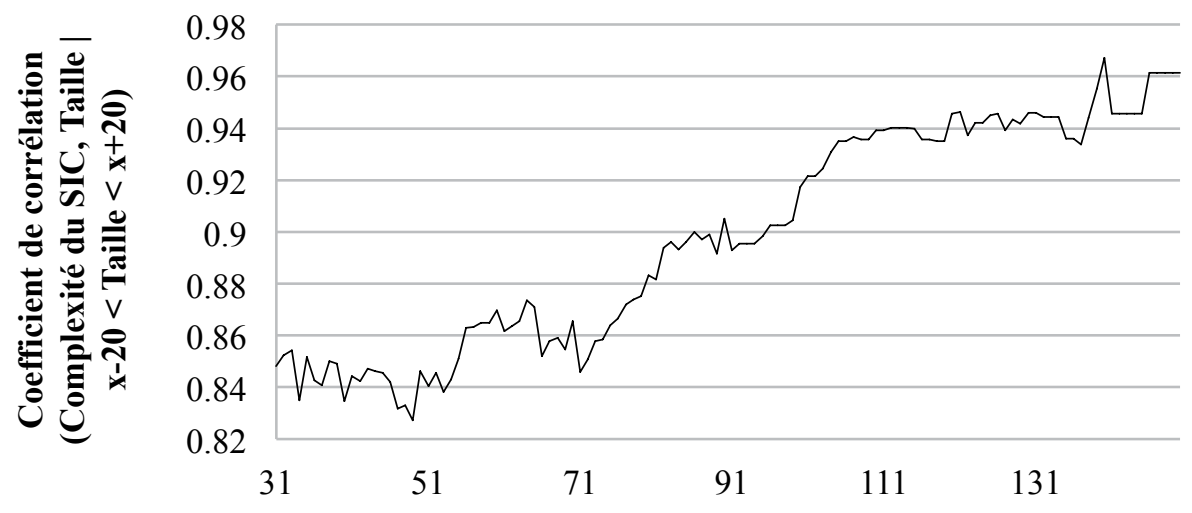

Taille de l'entreprise, $x$

FIGURE 2

\section{Diminution du coefficient de corrélation entre l'âge de l'entreprise et la complexité du système d'information comptable}

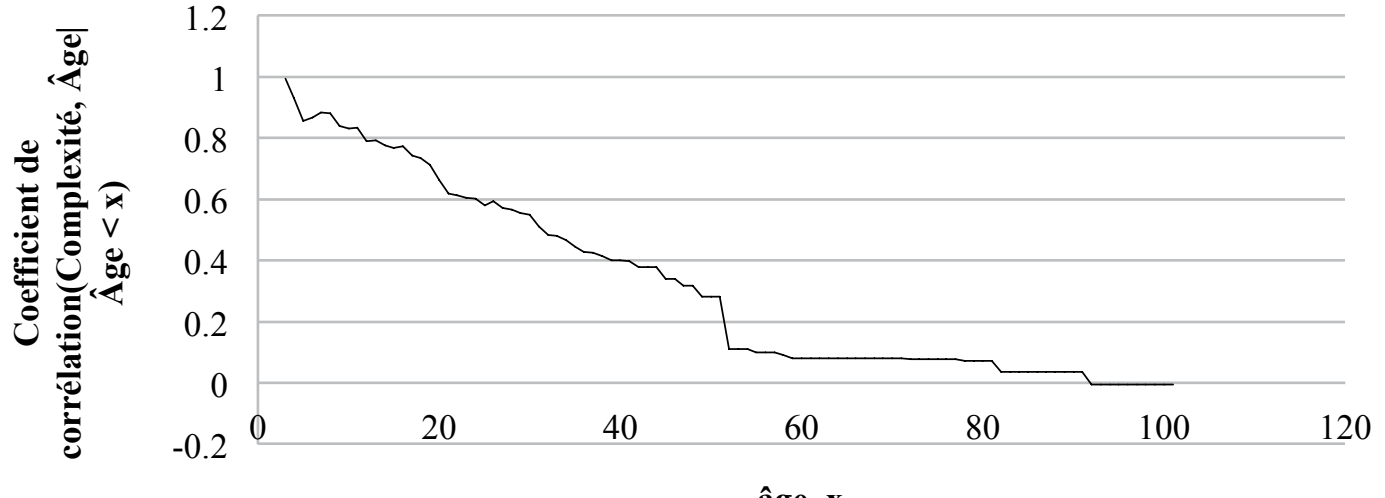

âge, $x$

et positif au seuil de $1 \%$ pour chacun des quatre modèles testés $(1 \mathrm{a}, 1 \mathrm{~b}, 1 \mathrm{c}$ et $1 \mathrm{~d})$.

Davila (2005) a mis en avant un comportement intéressant entre le pourcentage d'adoption d'un système de contrôle de gestion et la taille de l'entreprise. Dans son travail, ce pourcentage augmente jusqu'à atteindre une taille de 34 salariés, reste stable entre 34 et 75 salariés et crô̂t à nouveau au-delà. Suivant son étude, on peut supposer que la corrélation entre la taille et la complexité des systèmes d'information comptables diffère en fonction de la taille de l'entreprise. Pour tester cela, nous avons calculé un coefficient de corrélation mobile pour différentes tailles d'entreprises (figure 1).
La figure 1 montre une évolution «en escalier» de ce coefficient de corrélation mobile. Jusqu'à une taille d'entreprise de 51 salariés, le coefficient de corrélation fluctue autour d'un plateau égal à 0,84 . Entre 51 et 56 salariés ce coefficient augmente. Enfin, entre 56 et 71 salariés, ce coefficient se fixe autour de 0,86 et augmente fortement ensuite. Nous retrouvons donc cette évolution en escalier du coefficient de corrélation observé par Davila (2005), même si dans le cas des entreprises étudiées ici, les seuils diffèrent.

La littérature suggère par ailleurs l'existence de liens entre l'âge de l'entreprise et ses pratiques de gestion. Le tableau 7 montre que l'âge de l'entreprise a un impact négatif et significatif au seuil de $10 \%$ sur la complexité du SIC lorsque la variable culturelle retenue est l'individualisme 


\section{TABLEAU 8}

\section{Résultats obtenus avec l'algorithme du bootstrap $(\mathrm{N}=276)$}

\begin{tabular}{|c|c|c|c|c|c|c|c|c|}
\hline \multirow[t]{2}{*}{ Modèles } & \multicolumn{2}{|c|}{ 1a : test de H1 } & \multicolumn{2}{|c|}{$1 \mathrm{~b}:$ test de $\mathrm{H} 2$} & \multicolumn{2}{|c|}{$1 \mathrm{c}:$ test de $\mathrm{H} 3$} & \multicolumn{2}{|c|}{$1 \mathrm{~d}:$ test de $\mathrm{H} 4$} \\
\hline & Coefficient & (ES) & Coefficient & (ES) & Coefficient & (ES) & Coefficient & (ES) \\
\hline Constante & 6,65 & $(4,98)$ & $10,85^{* * *}$ & $(3,57)$ & $62,65^{* * *}$ & $(5,76)$ & $102,41^{* * *}$ & $(8,80)$ \\
\hline Âge de l'entreprise & $-0,04$ & $(0,07)$ & $-0,09^{*}$ & $(0,06)$ & $-0,03$ & $(0,07)$ & $-0,07$ & 0,06 \\
\hline Taille de l'entreprise & $0,06^{* * *}$ & $(0,01)$ & $0,07^{* * *}$ & $(0,01)$ & $0,06^{* * *}$ & $(0,01)$ & $0,06^{* * *}$ & $(0,02)$ \\
\hline $\begin{array}{c}\text { Niveau de formation } \\
\text { du dirigeant }\end{array}$ & $7,20^{* * *}$ & $(2,01)$ & $8,91^{* * *}$ & $(1,90)$ & $7,15^{* * *}$ & $(2,04)$ & $8,75^{* * *}$ & $(1,91)$ \\
\hline Expérience du dirigeant & $-0,65$ & $(1,36)$ & $-1,42$ & $(1,23)$ & $-0,64$ & $(1,37)$ & $-1,67$ & $(1,24)$ \\
\hline Dimension culturelle & $0,43^{* * *}$ & $(0,07)$ & $0,45^{* * *}$ & $(0,05)$ & $-0,58^{* * *}$ & $(0,09)$ & $-0,95^{* * *}$ & $(0,11)$ \\
\hline
\end{tabular}

Notes : ${ }^{* *}$ et ${ }^{* * *}$ rendent compte de valeurs de $\mathrm{p}$ associées aux hypothèses présentées inférieures à $5 \%$ et $1 \%$ respectivement. Les variables colinéaires ont été retirées. ES est l'erreur standard.

(test du modèle $1 b$ ). En revanche, cette variable a un effet négatif mais non significatif lorsque les variables culturelles retenues sont l'évitement de l'incertitude (test du modèle 1a), la masculinité/féminité (test du modèle 1c) et la distance hiérarchique (test du modèle 1d). Le modèle de Greiner (1972) permet de postuler que l'impact de l'âge de l'entreprise sur la complexité du système d'information comptable serait significatif dans un premier temps puis diminuerait à partir d'un certain seuil d'ancienneté. La figure 2 confirme ce résultat. Elle montre le résultat graphique du calcul d'un coefficient de corrélation entre l'âge de l'entreprise et la complexité du système d'information comptable pour des entreprises âgées de moins de $\mathrm{x}$ années. Ce test réalisé pour chacun des coefficients de corrélation montre qu'ils sont significativement différents de zéro jusqu'à la cinquante-etunième année $(\mathrm{p}<0,001$ pour Âge $<51 ; \mathrm{p}=0,064$ pour Âge $=52$ ). Au-delà, la relation entre l'âge de l'entreprise et la complexité du SIC n'est plus significative.

Avant d'exposer les tests de robustesse réalisés afin de montrer la fiabilité de nos résultats, nous avons réalisé des traitements pour vérifier l'absence de biais d'endogénéité.

\section{Contrôle de l'absence d'endogénéité et tests des hypothèses auxiliaires}

Le test d'Hausman réalisé ne conduit pas à rejeter l'hypothèse d'exogénéité de la taille de l'entreprise $(F=0,002 ; p=0,965)$. La taille de l'entreprise n'est pas déterminée par d'autres variables omises influençant aussi la complexité des systèmes d'information comptables. Ce résultat contribue à montrer que les études empiriques antérieures, qui se sont concentrées sur une population de PME d'un seul pays sans prendre en considération les dimensions de la culture nationale, ne devraient pas souffrir d'un biais d'endogénéité. Il constitue un indice de fiabilité de leurs résultats.
Nous avons estimé les paramètres des modèles 1a, 1b, $1 \mathrm{c}$ et $1 \mathrm{~d}$ avec la méthode des moindres carrées et celle du maximum de vraisemblance. L'usage de ces deux techniques a donné les mêmes résultats. Le test RESET de Ramsey (1969) a aussi été mobilisé. Ce test confirme la bonne spécification des modèles $1 \mathrm{a}, 1 \mathrm{~b}, 1 \mathrm{c}$ et $1 \mathrm{~d}$.

Par ailleurs, nous avons testé les hypothèses auxiliaires des moindres carrés ordinaires pour montrer l'adéquation du modèle que nous avons retenu aux données dont nous disposions. Nous avons utilisé pour cela les tests de BreuschGodfrey (Breusch, 1978), Breusch-Pagan (Breusch et Pagan, 1979), Shapiro-Wilk (Shapiro et Wilk, 1965) et de linéarité (Utts, 1982). D'autres tests sur les paquets «car», «nortest» et «lmtest» du logiciel $\mathrm{R}$ ont aussi été utilisés à des fins de triangulation. Ils ne conduisent pas à rejeter les hypothèses auxiliaires des modèles linéaires dont les résultats ont été présentés au point précédent.

Avant de discuter la contribution de nos résultats à la littérature, nous exposons les tests de robustesse réalisés afin de juger la fiabilité de nos résultats.

\section{Tests de ROBustesse}

Nous avons souligné qu'utiliser la production (et non l'utilisation) des données comptables pour mesurer la complexité du SIC constitue une limite de notre étude. Pour vérifier la robustesse de nos résultats et lever partiellement cette limite, nous avons réalisé les mêmes traitements que précédemment en retenant les mêmes variables explicatives et de contrôle, mais en retenant le score d'utilisation du système d'information comptable comme variable expliquée à la place du score de production. Ce travail a été réalisé sur la base des données issues des seuls travaux de Chapellier (1996) et Chapellier, Mohammed et Teller (2013) qui ont chacun intégré l'utilisation 
des données comptables dans le calcul de leur score de complexité du SIC. Les résultats sont identiques concernant les signes. Mais, les variables culturelles ont un effet moins significatif $(\mathrm{p}<0,02$, contre $\mathrm{p}<0,001)$. Sans la supprimer, ce test permet de relativiser cette limite de notre travail si l'on retient comme critère de décision un risque de première espèce usuel de $5 \%$.

Une autre limite de notre étude tient au fait que nous avons retenu les dimensions de la culture nationale marocaine à la place de celle de la Tunisie qui ne sont pas disponibles sur le site http://geert-hofstede.com. Pour vérifier la sensibilité de nos résultats, nous avons réalisé les mêmes tests tout d'abord en retirant les données tunisiennes de l'étude. Les résultats obtenus restent identiques à ceux obtenus initialement (les coefficients sont de mêmes signes et les degrés de signification sont tous inférieurs à 0,001 ). Nous avons ensuite utilisé les dimensions de la culture nationale libyenne, un pays proche géographiquement et culturellement de la Tunisie. Pour les quatre dimensions de la culture nationale, les conclusions restent identiques : les coefficients sont de mêmes signes et les degrés de signification sont tous inférieurs à 0,001 $(1,195,0,424,-1.673$ et $-0,881$ pour les dimensions «évitement de l'incertitude», «individualisme / collectivisme», «masculinité / féminité» et «distance hiérarchique»; $p<0,001$ ). Pour les quatre variables de contrôle, les degrés de signification et les estimations des paramètres de la régression restent aussi identiques au centième près. Sans la supprimer, cela permet de relativiser l'impact de cette limite sur nos résultats.

Nous avons enfin vérifié que nos inférences sont bonnes malgré l'absence de tirage aléatoire des répondants. Pour ce faire, nous avons fait 10000 rééchantillonnages. Lors de chaque rééchantillonnage, nous avons remplacé dans le modèle les aléas par des résidus bootstrap e*, obtenus par tirage avec remise des résidus de la régression dont les résultats ont été présentés dans le tableau 7. Cela nous a permis d'obtenir des effets moyens et des degrés de signification corrigés (tableau 8). Nous observons que les conclusions ne changent pas.

\section{Discussion et conclusion}

Cette étude visait à déterminer si la complexité des systèmes d'information comptables des dirigeants de PME est déterminée par les dimensions de la culture nationale, et à évaluer le risque de biais d'endogénéité dans les études antérieures.

L'impact de facteurs de contingence culturels sur la complexité des systèmes d'information comptables n'avait, comme souligné par Harrison et McKinnon (1999) et Chenhall (2007), fait l'objet d'aucune recherche. En cela, notre étude apporte un soutien à la théorie de la contingence culturelle en confirmant l'existence d'un lien entre les dimensions culturelles et la complexité des systèmes d'information comptables de PME françaises, syriennes et tunisiennes. Nous avons trouvé un lien positif et significatif entre les dimensions «évitement de l'incertitude» (H1) et «individualisme» (H2) et la complexité du système d'information comptable. L'existence d'un lien positif entre «masculinité» et complexité du système d'information comptable (H3) n'est en revanche pas validée. Nos résultats révèlent à l'inverse l'existence d'un lien significatif mais négatif entre ces deux variables : les SIC des PME françaises, nation jugée plus «féminine» par Hofstede que la Syrie et la Tunisie, sont significativement plus complexes que ceux des PME syriennes et tunisiennes. De même, l'absence supposée de lien entre la dimension «distance hiérarchique» et la complexité du système d'information comptable (H4) n'est pas validée. L'étude révèle l'existence d'un lien significatif et négatif entre ces deux variables. Ces résultats nous conduiront à exposer à la fin de cette conclusion une des limites de notre étude et une avenue de recherche future.

Notre étude donne ainsi un éclairage multiculturel sur les déterminants de la complexité des systèmes d'information comptables. Cela «déplace la conversation» (Huff, 1999) et «ouvre un champ» (Locke et Golden-Biddle, 1997). Nos résultats peuvent aider des dirigeants cherchant à développer leur activité à l'international car ils montrent que la complexité des systèmes d'information comptables en PME varie en fonction du contexte structurel (notamment la taille de l'entreprise), des caractéristiques individuelles des dirigeants (notamment son niveau de formation), mais aussi des dimensions culturelles du pays. L'adaptation des systèmes d'information comptables en PME relève donc d'une combinaison entre des facteurs de contingence structurels, individuels et culturels. Les recherches récentes sur le thème ont montré qu'il n'existe pas de norme universelle dictant un degré standard adéquat de recours aux données comptables. Notre étude montre qu'en fonction du contexte structurel, de leurs caractéristiques personnelles, mais aussi du contexte culturel, les dirigeants de PME français, syriens et tunisiens adaptent la complexité de leur système d'information comptable à la recherche d'un équilibre satisfaisant entre absence et excès de formalisation comptable.

Par ailleurs, la littérature récente (Chenhall et Moers, 2007; García Lara et al. 2007; Larcker et Rusticus, 2010; Tucker, 2011; Lennox et al., 2012) suggère que les résultats des études antérieures réalisées sur le thème des déterminants de la complexité des SIC pourraient être biaisés par l'endogénéité de variables que les auteurs ont supposées exogènes. Certains facteurs, telle la taille de l'entreprise directement liée à la structure des organisations (Chenhall, 2003) et indirectement à l'environnement économique et technique (MacIntosh, 1981), pourraient dépendre d'autres variables influençant aussi la complexité du système d'information comptable. Mais le test d'Hausman réalisé dans le cadre de notre étude ne confirme pas l'existence de biais d'endogénéité. La taille de l'entreprise ne semble donc pas déterminée par d'autres variables omises influençant aussi la complexité du système d'information comptable. Sans apporter de réponse définitive, ce résultat constitue un indice selon lequel les résultats des études antérieures qui se sont concentrées sur une population de PME d'un seul pays, ne devraient pas 
souffrir d'un biais d'endogénéité. Notre étude contribue ainsi à valider la fiabilité de leurs résultats.

Notre étude montre aussi l'évolution en escalier de la corrélation entre la taille de l'entreprise et la complexité du système d'information comptable. Nous retrouvons ici le même phénomène inexpliqué observé par Davila (2005) dans une population de jeunes entreprises de petite taille de la Silicon Valley, même si dans notre étude, les seuils diffèrent quelque peu des siens. Le concept de crise de la croissance de Greiner peut être à notre sens utilisé pour expliquer ce résultat. Selon Greiner, la croissance de l'entreprise est un phénomène ponctué par des «phases d'évolution» caractérisées par une croissance stable marquée par des changements lents et progressifs. Entre ces phases stables de croissance ont lieu des «phases de révolution» se caractérisant par des changements abrupts et des sauts qualitatifs. Au mieux de nos connaissances, le scénario d'évolution de Greiner n'a qu'un statut théorique (Torrès-Blay, 2004, p. 158). Aucune étude n'a à ce jour identifié précisément les seuils critiques au-delà desquels se déclenchent les crises impactant le système de contrôle de gestion. Notre étude présente ici une contribution théorique et managériale en confirmant le constat réalisé par Davila d'une croissance en escalier du coefficient de corrélation mobile entre la taille de l'entreprise et la complexité du système d'information comptable, et en proposant des seuils en nombre d'employés permettant d'anticiper «les crises » au sens de Greiner : au-delà de 51, 71 et 97 employés, surviendraient des crises de croissance qui déboucheraient sur un système d'information comptable plus complexe. À ces seuils, le coefficient de corrélation entre la complexité du système d'information comptable et la taille de l'entreprise atteint un plateau plus élevé.

Notre étude montre enfin que l'impact de l'âge de l'entreprise sur la complexité du système d'information comptable est significatif dans un premier temps puis diminue à partir d'un certain seuil d'ancienneté. Elle montre que les coefficients de corrélation entre l'âge de l'entreprise et la complexité du système d'information comptable sont significativement différents de zéro jusqu'à la cinquante-et-unième année mais qu'au-delà, la relation entre l'âge de l'entreprise et la complexité du SIC n'est plus significative.

Au-delà de ces contributions théoriques et managériales, notre étude présente des limites qui pourront être levées par des recherches futures. Premièrement, notre étude appréhende la culture nationale à travers les dimensions d'Hofstede (1980). Ce choix tient au fait que les travaux de cet auteur sont les plus cités dans la littérature sur la culture. Baskerville (2003) a dénombré 712 articles dans des revues en sciences de gestion citant l'ouvrage «Culture's consequences : international differences in work-related values » dans ses différentes éditions. Ils sont aussi les plus dupliqués : Hofstede dénombre, dans son dernier ouvrage coécrit avec son fils et Minkov en 2010, 107 pays où ses recherches ont été dupliquées. Les dimensions d'Hofstede ont toutefois souvent été critiquées par des auteurs dénonçant une approche trop simpliste et trop quantitative de la culture, un concept selon eux complexe nécessitant un cadre d'analyse plus fin qu'une étude par questionnaire (McSweeney, 2002; Baskerville, 2003; Fougère et Moulettes, 2005; Joannidès, 2011; Livian, 2011). Il serait ainsi intéressant d'appréhender la culture nationale dans de futures études avec d'autres dispositifs, plus qualitatifs, inspirés de travaux de sociologues ou d'anthropologues.

Deuxièmement, une période de 14 et 15 ans sépare le recueil des données de l'étude française des études tunisienne et syrienne. La complexité des SIC a pu évoluer de façon significative durant cette période. De nouveaux outils de gestion ont pu se diffuser dans les petites et moyennes entreprises, en lien notamment avec l'importance prise par les outils informatiques et l'apparition d'Internet. Un autre problème, souligné par Chenhall (2003), est l'utilisation de dimensions de la culture nationale évaluées il y a maintenant plus de trente ans. Ces décalages temporels limitent notre étude. Il conviendrait dans de futures recherches sur le sujet de vérifier la pertinence de nos résultats en réalisant la même étude, au même moment, dans différentes aires culturelles, en mesurant à nouveau les dimensions de la culture.

Troisièmement, utiliser la production (et non l'utilisation) des données comptables pour mesurer la complexité du SIC constitue une limite de notre étude. Pour vérifier la robustesse de nos résultats et lever partiellement cette limite, nous avons réalisé les mêmes traitements en retenant les mêmes variables explicatives et de contrôle, mais en prenant en considération le score d'utilisation du système d'information comptable comme variable expliquée à la place du score de production. Cela nous a conduits à exclure de l'analyse les données issues de l'étude de Ben Hamadi et Chapellier (2012) puisque celleci n'a pas retenu «l'utilisation» pour évaluer la complexité des SIC. Les résultats sont identiques concernant les signes mais les variables culturelles ont un effet moins significatif ( $\mathrm{p}<0,02$ contre $\mathrm{p}<0,001)$. Cela permet de relativiser cette limite mais ne l'élimine pas.

Quatrièmement, l'utilisation des dimensions de la culture marocaine à la place de celles de la culture tunisienne pourrait biaiser nos résultats. Pourtant, le retrait des données tunisiennes ne change en rien nos résultats, tout comme l'utilisation des dimensions de la culture libyenne (un autre pays proche géographiquement et culturellement de la Tunisie) à la place des dimensions de la culture marocaine. Cela pondère cette limite mais ne la supprime pas et montre l'utilité, dans de futurs travaux, d'évaluer les dimensions de la culture dans d'autres pays pour faciliter la réalisation d'études comparatives multinationales.

Ces limites ouvrent des perspectives de recherches intéressantes que nous comptons exploiter à travers la mise en œuvre de nouvelles études portant sur les SIC des dirigeants de PME. Une multiplication d'analyses en profondeur, réalisées dans différents pays, permettrait de mieux comprendre comment, avec un système d'information comptable adapté à leurs besoins, à leurs compétences, au contexte structurel 
et à la culture du pays, une fraction significative de dirigeants de PME parvient à des représentations riches et variées leur permettant de piloter efficacement leur organisation.

\section{Bibliographie}

Abdel-Kader, M.; Luther, R. (2008). «The impact of firm characteristics on management accounting practices : A UK-based empirical analysis», The British Accounting Review, vol. 40, $\mathrm{n}^{\circ} 1, \mathrm{p} .2-27$.

Affes, H.; Chabchoub, A. (2007). «Le système d'information comptable : les déterminants de ses caractéristiques et son impact sur la performance financière des PME en Tunisie», La Revue des Sciences de Gestion, Direction et Gestion, $\mathrm{n}^{\circ}$ 224-225, p. 59-68.

Al-Omiri, M.; Drury, C. (2007). «A survey of factors influencing the choice of product costing systems in UK organizations", Management Accounting Research, vol. 18, n 4, p. 399-424.

Baskerville, R. F. (2003). «Hofstede never studies culture», Accounting, Organizations and Society, vol. 28, n ${ }^{\circ}$ 1, p. 1-14.

Bellman, R. (1961). Adaptive control processes : a guided tour. Princeton University Press, $255 \mathrm{p}$.

Ben Hamadi, Z.; Chapellier, P. (2012). «Le système de données comptables des dirigeants de PME tunisiennes : complexité et déterminants », Management International, vol. 16, $\mathrm{n}^{\circ} 4$, p. $151-167$.

Benjamini, Y.; Yekutieli, D. (2001). «The control of the false discovery rate in multiple testing under dependency », Annals of Statistics, vol. $29, \mathrm{n}^{\circ} 4$, p. $1165-1188$.

Bergeron, H. (1996). Différenciation des systèmes de données et représentations en contrôle de gestion : essai d'observation et d'interprétation. Thèse de doctorat, Université de Montpellier II.

Bescos, P. L.; Cauvin, E.; Langevin, P.; Mendoza, C. (2004). «Critiques du budget : une approche contingente», Comptabilité-Contrôle-Audit, vol. 10, $\mathrm{n}^{\circ}$ 1, p. 165-185.

Bouquin, H. (1997). Le contrôle de gestion. $3^{\text {ème }}$ édition. Paris Presses Universitaires de France. 384 p.

Breusch, T. S. (1978). «Testing for Autocorrelation in Dynamic Linear Models», Australian Economic Papers, vol. 17, $\mathrm{n}^{\circ} 31$, p. 334-355.

Breusch, T. S.; Pagan, A. R. (1979). «A Simple Test for Heteroscedasticity and Random Coefficient Variation», Econometrica, vol. 47, $\mathrm{n}^{\circ}$ 5, p. 1287-1294.

Bruns, W. J.; Waterhouse, J. H. (1975). «Budgetary control and organization structure », Journal of Accounting Research, vol. $13, \mathrm{n}^{\circ} 2$, p. $177-203$.

Camerer, C.; Vepsalainen, A. (1988). «The economic efficiency of corporate culture», Strategic Management Journal, vol. 9, $\mathrm{n}^{\circ} \mathrm{S} 1, \mathrm{p} .115-126$.

Cameron, K. S.; Quinn, R. E. (2006). Diagnosing and changing organizational culture based on the competing values framework. San Francisco : Jossey-Bass, 288 p.

Chapellier, P. (1996). «Données comptables de gestion et système d'information du dirigeant de PME», Système d'Information et Management, vol. 2, $\mathrm{n}^{\circ}$, p. 23-41.
Chapellier, P. (2011). Vers un modèle de gestion hybride pour le dirigeant de PME : Une étude de la triangulation entre système d'information formel, recours à l'expert et mètis du dirigeant. Habilitation à Diriger des Recherches - Université de Nice Sophia Antipolis.

Chapellier, P.; Mohammed, A.; Teller, R. (2013). «Le système d'information comptable des dirigeants de PME syriennes : complexité et contingences », Management et Avenir, vol. 65, $\mathrm{n}^{\circ}$ 7, p. 48-72.

Chapman, C. S. (1997). «Reflections on a contingent view of accounting», Accounting, Organizations and Society, vol. 22, $\mathrm{n}^{\circ} 2$, p. 189-205.

Chenhall, R. H. (2003). «Management control systems design within its organizational context : findings from contingencybased research and directions for the future», Accounting, Organizations and Society, vol. 28, $\mathrm{n}^{\circ} 2-3$, p. 127-168.

Chenhall, R. H. (2007). "Theorizing Contingencies in Management Control Systems Research», dans C. S. Chapman; A. G. Hopwood; M. D. Shields (sous la coordination de), Handbook of Management Accounting Research. Oxford : Elsevier, p. 163-205.

Chenhall, R. H.; Moers, F. (2007). «The Issue of Endogeneity within Theory-Based, Quantitative Management Accounting Research», European Accounting Review, vol. 16, $\mathrm{n}^{\circ}$, p. 173-195.

Chenhall, R. H.; Morris, D. (1986). «The Impact of Structure, Environment, Perceived on the Interdependence Usefulness of Management Systems Accounting», Accounting Review, vol. $61, \mathrm{n}^{\circ} 1$, p. 16-35.

Chiapello, E. (1996). «Les typologies des modes de contrôle et leurs facteurs de contingence : Un essai d'organisation de la littérature », Comptabilité-Contrôle-Audit, vol. 2, $\mathrm{n}^{\circ} 2$, p. 51-74.

Chong, V. K. (1996). «Management accounting systems, task uncertainty and managerial performance : a research note», Accounting, Organizations and Society, vol. 21, $\mathrm{n}^{\circ} 5$, p. 415-421.

Chong, V. K. (1998). «Testing the contingency "fit" between management accounting systems and managerial perfomance : A research note on the moderating role of tolerance for ambiguity », British Accounting Review, vol. 30, n 4, p. 331-342.

Chong, V. K.; Chong, K. M. (1997). «Strategic choices, environmental uncertainty and SBU performance : a note on the intervening role of management accounting systems », Accounting and Business Research, vol. 27, $n^{\circ} 4$, p. 268-276.

Covaleski, M. A.; Dirsmith, M. W.; Samuel, S. (1996). «Managerial Accounting Research : The Contributions of Organizational and Sociological Theories», Journal of Management Accounting Research, vol. 8, p. 1-36.

Crozier M.; Friedberg E. (1977). L'acteur et le système. Paris : Seuil, $436 \mathrm{p}$.

Davila, T. (2005). «An exploratory study on the emergence of management control systems : formalizing human resources in small growing firms », Accounting, Organizations and Society, vol. $30, \mathrm{n}^{\circ} 3$, p. $223-248$.

Denison, D. R.; Misra, A. K. (1995). «Toward a theory of organizational culture and effectiveness », Organization Science, vol. $6, \mathrm{n}^{\circ} 2$, p. 204-223. 
Denison, D. R.; Spreitzer, G. M. (1991). «Organizational culture and organization development : A competing values approach», Research in Organizational Change and Development, vol. 5, p. 1-21.

Dupuy Y.; Kalika M.; Marmuse C.; Trahand, J. (1989). Les systèmes de gestion, introduction au soft management. Paris : Vuibert, $232 \mathrm{p}$.

Evrard, Y.; Pras, B.; Roux, E. (2009). Market : études et recherche en marketing. $3^{\text {ème }}$ édition, Paris : Dunod, $704 \mathrm{p}$.

Flacke, K.; Segbers, K. (2005). «Does managerial accounting follow entrepreneurial characteristics? Results of an empirical analysis of german SME», working paper, University of Munster.

Flamholtz, E. G. (1986). How to Make The Transition From an Entrepreneurship to a professionally Managed Firm. San Francisco : Jossey-Bass, $231 \mathrm{p}$.

Fougere, M.; Moulettes, A. (2005). «Cross-cultural management discourse : ideas of democracy, development, modernity and progress in Hofstede's cultures consequences », $4^{\text {th }}$ International Critical Management Studies Conference, Cambridge.

García Lara, J. M.; García Osma, B.; Penalva, F. (2007). «Accounting conservatism and corporate governance», Review of Accounting Studies, vol. 14, $\mathrm{n}^{\circ}$ 1, p. 161-201.

Gerdin, J. (2005). «Management accounting system design in manufacturing departments : an empirical investigation using a multiple contingencies approach», Accounting, Organizations and Society, vol. 30, $\mathrm{n}^{\circ}$ 2, p. 99-126.

Germain, C. (2004). «La contingence des systèmes de mesure de la performance : les résultats d'une recherche empirique sur le secteur des PME», Finance Contrôle Stratégie, vol. 7, $\mathrm{n}^{\circ} 1$, p. 33-52.

Greiner, L. E. (1972). «Evolution and revolution as organizations grow », Harvard Business Review, vol. 76, n 3, p. 3-11.

Gul, F. A. (1991). «The effects of management accounting systems and environmental uncertainty on small business managers' performance», Accounting and Business Research, vol. $22, n^{\circ} 85$, p. $57-61$.

Hambrick, D. C.; Mason, P. A. (1984). «Upper Echelons : The Organisation as a Reflection of Its Top Managers », Academy of Management Review, vol. 9, $\mathrm{n}^{\circ}$ 2, p. 193-206.

Harrison, G. L.; McKinnon, J. L. (1999). «Cross-cultural research in management control systems design : a review of the current state», Accounting, Organizations and Society, vol. 24, $\mathrm{n}^{\circ}$ 5-6, p. 483-506.

Hausman, J. A. (1978). «Specification Tests in Econometrics», Econometrica, vol. 46, $\mathrm{n}^{\circ}$ 6, p. 1251-1271.

Hofstede, G. (1980). Culture's consequences : international differences in work-related values. Beverly Hills : Sage, 327 p.

Hofstede, G. (1991). Cultures and organizations : software of the mind. Londres : McGraw-Hill UK, 576 p.

Hofstede, G.; Neuigen, B.; Ohavy, D. D.; Sanders, G. (1990). «Measuring organizational culture : A qualitative and quantitative study across twenty cases », Administrative Science Quarterly, vol. 35, n², p. 286-316.

Hofstede, G. (1998). «Attitudes, Values and Organization and Culture : Disentangling the Concepts », Organization Studies, vol. 19, n 3, p. 477-493.
Hofstede, G.; Hofstede, G. J.; Minkov, M. (2010). Cultures et organisations : comprendre nos programmations mentales. $3^{\text {ème }}$ édition, Paris : Pearson, $512 \mathrm{p}$.

Holmes S.; Nicholls D. (1989). «Modelling the accounting information requirement of small business", Accounting and Business Research, vol. 19, $\mathrm{n}^{\circ}$ 74, p. 143-150.

Huff, A. S. (1999). Writing for scholarly publication. Londres : Sage, $200 \mathrm{p}$.

Jänkälä, S. (2007). Management control systems (MCS) in the small business context : Linking effects of contextual factors with MCS and financial performance of small firms. Oulu University Press.

Joannides, V. (2011). «Apport de l'ethnicité à la culture en sciences de gestion», Finance Contrôle Stratégie, vol. 14, $\mathrm{n}^{\circ} 1$, p. 33- 68 .

Khandwalla, P. N. (1972). «The effects of different types of competition on the use managerial controls », Journal of Accounting Research, vol. 10, $\mathrm{n}^{\circ} 2$, p. 275-285.

Laitinen, E. (2001). «Management Accounting Change In Small Technology Companies : Towards a Mathematical Model of Technology Firm», Management Accounting Research, vol. $12, \mathrm{n}^{\circ} 4$, p. 507-541.

Larcker, D. F.; Rusticus, T. O. (2010). «On the use of instrumental variables in accounting research », Journal of Accounting and Economics, vol. 49, $\mathrm{n}^{\circ}$ 3, p. 186-205.

Lavigne, B. (2002). «Contribution à l'étude de la genèse des états financiers des PME», Comptabilité- Contrôle-Audit, vol. 8, $\mathrm{n}^{\circ} 1$, p. 25-44.

Lavigne, B.; St-Pierre, J. (2002). «Association entre le système d'information comptable des PME et leur performance financière», $6^{\text {ème }}$ Congrès International Francophone sur la PME, Montréal.

Lennox, C. S.; Francis, J. R.; Wang, Z. (2012). «Selection Models in Accounting Research», Accounting Review, vol. 87, $\mathrm{n}^{\circ} 2$, p. 589-616.

Livian, Y. F. (2011). «Pour en finir avec Hofstede : Renouveler les recherches en management interculturel», Communication à la première conférence annuelle ATLAS / AFMI, Paris.

Locke, K.; Golden-Biddle, K. (1997). «Constructing Opportunities for Contribution : Structuring Intertextual Coherence and "Problematizing" in Organizational Studies", Academy of Management Journal, vol. 40, $\mathrm{n}^{\circ}$ 5, p. 1023-1062.

Lorino, P. (1995). Comptes et récits de la performance. Paris : Organisation, $287 \mathrm{p}$.

MacArthur, J. B. (2006). «Cultural Influences on German versus U.S. Management Accounting Practices», Management Accounting Quarterly, vol. 7, $\mathrm{n}^{\circ}$ 2, p. 10-16.

MacIntosh, N. B. (1981). "A Contextual Model of Information Systems », Accounting, Organizations and Society, vol. 6, $\mathrm{n}^{\circ} 1$, p. 39-52.

McSweeney, B. (2002). «Hofstede model of national, cultural differences : a triumph of faith, a failure of analysis », Human Relations, vol. 55, $\mathrm{n}^{\circ} 1$, p. 89-118.

Mia, L.; Chenhall, R. H. (1994). «The Usefullness of Management Accounting Systems, Functional Differentiation and Managerial Effectiveness », Accounting, Organizations and Society, vol. 19, ${ }^{\circ}$ 1, p. 1-13. 
Mintzberg H. (1982). Structure et dynamique des organisations, Paris : Organisation, $434 \mathrm{p}$.

Mintzberg, H. (2006). Structure et dynamique des organisations. $19^{\text {ème }}$ édition, Paris : Organisation, p.434

Moores, Y.; Yuen, S. (2001). «Management accounting systems and organizational configuration : a life-cycle perspective», Accounting, Organizations and Society, vol. 26, n 4 , p. 351-389.

Nadeau, R.; Martel, J.; Martel, C.; M’Zali, B. (1988). «L'utilisation des méthodes quantitatives pour les décisions de gestion dans les PME québécoises : une étude empirique», Papier de recherche Université de Laval, GRADE RR 88, Québec, Novembre.

Négrier, E. (2004). «Les échelles politiques : État, pouvoir local et territoire dans la construction de nouvelles institutions métropolitaines en France», Colloque La gouvernance métropolitaine : recherche de cohérence dans la complexité, Montréal.

Nobre, T. (2001). «Méthodes et outils du contrôle de gestion dans les PME», Finance Contrôle Stratégie, vol. 4, n 2, p. 119-148.

Nyengue Edimo, P. (2006). L'organisation du système d'information comptable des entreprises camerounaises : essai d'observation et interprétation des pratiques. Doctorat en Sciences de Gestion, Université Bordeaux IV.

O’Reilly, C. A. III; Chatman, J.; Caldwell, D. F. (1991). «People and Organizational culture : A profile comparison approach to assessing person-organization fit», Academy of Management Journal, vol. 34, n³, p. 487-516.

Ramsey, J. B. (1969). «Tests for Specification Errors in Classical Linear Least-Squares Regression Analysis », Journal of the Royal Society. Series B (Methodological), vol. 31, n 2, p. 350-371.

Raymond, L. (1985). «Organizational Characteristics and the Success of MIS in the Context of Small Business », MIS Quarterly, vol. 9, $\mathrm{n}^{\circ}$ 1, p. 37-52.

Reid, G. C.; Smith, J. A. (2000). «The impact of contingencies on management accounting system development», Management Accounting Research, vol. 11, n 4, p. 427-450.

Reix, R. (1984). «Quelques facteurs affectant l'utilisation d'informations de caractère comptable », Actes du congrès de l'Association Française de Comptabilité, Nice, p. 357-370.

Rousseau, D. M. (1990). «Organizational culture : The case for multiple methods», dans B. Schneider (sous la coordination de), Organizational climate and culture. San Francisco : Jossey-Bass, p. 153-192.

Saboly, M. (1994). Les déterminants de la qualité des produits comptables : le rôle du dirigeant. Doctorat en Sciences de Gestion, Université de Poitiers.

Santin, S.; Van Caillie D. (2008). «Le design du système de contrôle de gestion des PME : une quête de stabilité

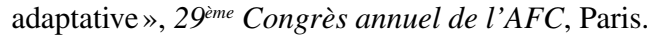

Sathe, V. (1975). «Contingency theories of organizational», dans J. L. Livingstone (sous la coordination de), Managerial Accounting : The Behavioural Foundations. Colombus : Grid, p. 51-63.

Schein, E. H. (1985). Organizational culture and leadership. San Francisco : Jossey-Bass, $436 \mathrm{p}$.

Schein, E. H. (1996). "Culture : The Missing Concept in Organization Studies », Administrative Science Quarterly, vol. $41, \mathrm{n}^{\circ} 2$, p. 229-240.
Shapiro, S. S.; Wilk, M. B. (1965). «An analysis of variance test for normality (complete samples)», Biometrika, vol. 52, $\mathrm{n}^{\circ} 3-4$, p. 591-611.

Thiétart, R. A. (2007). Méthodes de recherche en management. $3^{\text {ème }}$ édition, Paris : Dunod, $560 \mathrm{p}$.

Tillema, S. (2005). «Towards an integrated contingency framework for MAS sophistication », Management Accounting Research, vol. 16, n 1, p. 101-129.

Torrès-Blay, O. (2004). Économie d'entreprise : organisation, stratégie et territoire à l'aube de la nouvelle économie. $2^{\text {ème }}$ édition, Paris : Economica, $324 \mathrm{p}$.

Tucker, J. W. (2011). «Selection bias and econometric remedies in accounting and finance research », Journal of Accounting Literature, vol. 29, p. 31-57.

Utts, J. M. (1982). «The rainbow test for lack of fit in regression », Communications in Statistics - Theory and Methods, vol. $11, \mathrm{n}^{\circ} 24$, p. 2801-2815.

Van Caillie, D. (2002). «L'approche en «coût client», une méthodologie de calcul des coûts propre à l'entreprise orientée «client»», 23 ème Congrès l'Association Française de Comptabilité, Montréal.

Weick, K. E. (1979). The social psychology of organizing. $2^{\text {ème }}$ édition. Addison-Wesley : Reading, 294 p. 


\section{ANNEXE 1}

\section{Items utilisés pour évaluer la complexité du système d'information comptable par la production}

\section{I) COMPTABILITÉ gÉNÉRALE :}

1. Combien de temps après la date de clôture disposez-vous d'un bilan et d'un compte de résultat utilisables à des fins de gestion?

\section{प Moins d'1 semaine \\ 1 semaine à 1 mois \\ ㄱ 1 à 2 mois \\ 口 2 à 3 mois \\ $\square$ Plus de 3 mois}

2. Préparez-vous des états financiers intermédiaires?

$\square$ Oui

$\square$ Non (Si la réponse est Non, veuillez passer directement à la question 6)

3. L'établissement d'une situation intermédiaire se fait tous les :

$\square$ Mois

$\square$ Trimestres

$\square$ Semestres

$\square$ Ponctuellement (précisez)

4. Quels sont les délais nécessaires à l'établissement des situations intermédiaires?

Moins d'1 semaine

1 semaine à 1 mois

$\square$ Plus d'un mois

5. L'élaboration des situations intermédiaires présente un caractère plutôt :

Général et approximatif

Complet et détaillé

$\begin{array}{lllll}1 & 2 & 3 & 4 & 5\end{array}$

\section{II) Système de Calcul de coûts}

6. Existe-t-il, dans votre entreprise, un système de calcul de coûts?

Oui

$\square$ Non (Si la réponse est Non, veuillez passer directement à la question 12)

7. Votre entreprise dispose-t-elle des informations suivantes?

\section{OUI NON}

Coûts fonctionnels globaux

Coûts détaillés par produit ou par chantier

Coûts détaillés par atelier ou par service
8. Quels types de coûts calculez-vous? (plusieurs cases peuvent être cochées)

OUI NON

Coût variable

Coût direct

Coût complet

Coût standard

$\mathrm{ABC}$

Autres (précisez)

9. Quelle est, dans le domaine des coûts, la fréquence de préparation des rapports de coûts?
Gebdomadaire
Mensuelle
$\square$ Trimestrielle
a Semestrielle
a Annuelle
口 Ponctuelle (précisez)

10. En général, quel est le délai nécessaire pour produire les rapports relatifs aux coûts?

En temps réel

$\square 1$ jour

plusieurs jours

그 3 semaine(s)

1 à plusieurs mois

11. De manière générale, comme jugez-vous le degré de détail des rapports de coûts?

Plutôt sommaire

Plutôt détaillé

$$
\begin{array}{lllll}
1 & 2 & 3 & 4 & 5
\end{array}
$$

\section{III) Pratiques budgétaires et Prévisionnelles}

12. Existe-t-il dans votre entreprise un système budgétaire ou de prévision?

Oui

$\square$ Non (Si la réponse est Non, veuillez passer directement à la question 22)

13. Les activités ou fonctions suivantes font-elles l'objet de budgets ou de prévisions?

Achat

Production

Ventes
OUI NON

$\begin{array}{ll}\square & \square \\ \square & \square \\ \square & \square\end{array}$




\section{OUI NON}

Investissement

Trésorerie

Autres (précisez)

14. Elaborez-vous un bilan et/ou un compte de résultat prévisionnel(s)?

$\square$ Oui

$\square$ Non

15. Votre cadre budgétaire est :

Global

Ventilé par atelier ou par service

1

2

3

4

5

16. Vos prévisions couvrent une période :

$\square$ Hebdomadaire

$\square$ Mensuelle

$\square$ Trimestrielle

$\square$ Semestrielle

$\square$ Annuelle

$\square$ Ponctuelle (précisez)

17. Existe-t-il un système de suivi des prévisions budgétaires (un système de contrôle budgétaire)?

$\square$ Oui

Non (Si la réponse est Non, veuillez passer directement à la question 22)

18. En général, quel est le délai nécessaire pour produire les données relatives à ce suivi?

$\square$ En temps réel

$\square 1$ jour

$\square$ plusieurs jours

- 1 à 3 semaine(s)

$\square 1$ à plusieurs mois

19. Les comparaisons entre les réalisations et les prévisions sont effectuées tous les

\section{$\square$ Semaines \\ $\square$ Mois \\ $\square$ Trimestres \\ $\square$ Semestres \\ $\square$ Ans \\ a Jamais}

20. Les révisions de budgets ou de prévisions en cours d'année sont :

Exclues (aucune révision)

Régulières et systématiques

$$
1
$$

2
21. Compte tenu des causes d'écarts retenant l'attention, l'analyse d'écarts entre le réel et le budget vous semble :

Limitée

Complète

$\begin{array}{lllll}1 & 2 & 3 & 4 & 5\end{array}$

\section{IV) Pratiques relatives aux tableaux de bord}

22. Tenez-vous un tableau de bord?

$\square$ Oui

Non (Si la réponse est Non, veuillez passer directement à la question 25)

23. Votre tableau de bord est mis à jour :

$\square$ Toutes les semaines

$\square$ Tous les mois

$\square$ Tous les trimestres

$\square$ Tous les semestres

$\square$ Tous les ans

$\square$ Autres (précisez)

24. Quelles sont les principales informations contenues dans votre tableau de bord? 